\title{
Understanding cirrus ice crystal number variability for different heterogeneous ice nucleation spectra
}

\author{
Sylvia C. Sullivan ${ }^{1}$, Ricardo Morales Betancourt ${ }^{2}$, Donifan Barahona ${ }^{3}$, and Athanasios Nenes ${ }^{1,4,5,6}$ \\ ${ }^{1}$ Department of Chemical and Biomolecular Engineering, Georgia Institute of Technology, Atlanta, GA 30332, USA \\ ${ }^{2}$ Department of Civil and Environmental Engineering, University of Los Andes, Bogotá, Colombia \\ ${ }^{3}$ NASA Goddard Space Flight Center, Greenbelt, MD 20771, USA \\ ${ }^{4}$ Department of Earth and Atmospheric Sciences, Georgia Institute of Technology, Atlanta, GA 30332, USA \\ ${ }^{5}$ ICE-HT, Foundation for Research and Technology, Hellas, 26504 Patras, Greece \\ ${ }^{6}$ IERSD, National Observatory of Athens, Palea Penteli, 15236, Greece \\ Correspondence to: Athanasios Nenes (athanasios.nenes@gatech.edu)
}

Received: 16 June 2015 - Published in Atmos. Chem. Phys. Discuss.: 11 August 2015

Revised: 27 November 2015 - Accepted: 5 January 2016 - Published: 3 March 2016

\begin{abstract}
Along with minimizing parameter uncertainty, understanding the cause of temporal and spatial variability of the nucleated ice crystal number, $N_{\mathrm{i}}$, is key to improving the representation of cirrus clouds in climate models. To this end, sensitivities of $N_{\mathrm{i}}$ to input variables like aerosol number and diameter provide valuable information about nucleation regime and efficiency for a given model formulation. Here we use the adjoint model of the adjoint of a cirrus formation parameterization (Barahona and Nenes, 2009b) to understand $N_{\mathrm{i}}$ variability for various ice-nucleating particle (INP) spectra. Inputs are generated with the Community Atmosphere Model version 5, and simulations are done with a theoretically derived spectrum, an empirical lab-based spectrum and two field-based empirical spectra that differ in the nucleation threshold for black carbon particles and in the active site density for dust. The magnitude and sign of $N_{\mathrm{i}}$ sensitivity to insoluble aerosol number can be directly linked to nucleation regime and efficiency of various INP. The labbased spectrum calculates much higher INP efficiencies than field-based ones, which reveals a disparity in aerosol surface properties. $N_{\mathrm{i}}$ sensitivity to temperature tends to be low, due to the compensating effects of temperature on INP spectrum parameters; this low temperature sensitivity regime has been experimentally reported before but never deconstructed as done here.
\end{abstract}

\section{Introduction}

Aerosol-cloud interactions remain the largest source of uncertainty in projections of anthropogenic climate change, and aerosol-ice interactions, in particular, are poorly understood (Boucher et al., 2013). Atmospheric aerosol may modulate the properties of pure ice clouds by providing particles upon which new ice crystals form. Cirrus clouds control moisture transfer into the lower stratosphere and can have a net warming effect (e.g., Chen et al., 2000; Brewer, 1949; Jensen et al., 1994).

Ice crystals within cirrus clouds can be formed in a variety of ways. Heterogeneous nucleation refers to the formation of ice on an aerosol surface, and the portion of aerosol upon which ice forms this way are called ice-nucleating particles (INP). There are several modes of heterogeneous freezing: in deposition nucleation, vapor deposits directly onto an aerosol; in condensation freezing, the aerosol acts first as a cloud condensation nucleus and then immediately as an INP; and in immersion freezing, an aerosol submerged for some time in supercooled liquid eventually initiates ice formation. Ice crystals may also form directly from an aqueous phase through homogeneous nucleation, typically at temperatures below about $235 \mathrm{~K}$ (Pruppacher and Klett, 1997). Aircraft measurements of relative humidity and ice crystal number concentrations indicate that heterogeneous nucleation is dominant for synoptic cirrus over North and Central America (Cziczo et al., 2013). But both mechanisms can be active in 
cirrus clouds, and the competition for water vapor between homogeneous and heterogeneous ice nucleation must be included in cirrus formation parameterizations (Barahona and Nenes, 2008, 2009a, b; Lin et al., 2005).

Much effort has been devoted to studying heterogeneous ice nucleation on a fundamental level (e.g., Reinhardt and Doye, 2014; Lupi et al., 2014; Cox et al., 2015). Ice nucleation can be understood as the formation of an ice germ in the vicinity of an active site. The nature of active sites is unknown, but current understanding suggests that they promote ordering of the water molecule layers near the particle surface. The active site density refers to the number of these sites per unit of aerosol surface area. A particle with more surface area will tend to have more active sites and nucleate at higher temperatures (or lower supersaturations); however, each active site varies in its efficiency, so that contact angle or site density distributions are necessary (Barahona, 2012; Kulkarni et al., 2012).

While Köhler theory is the accepted framework to describe droplet activation, nothing analogous exists for ice. Two conceptual paradigms are currently in use: stochastic and singular freezing (Pruppacher and Klett, 1997; Vali, 2014). In the stochastic paradigm, water molecules fluctuate randomly to and from a particle surface with some probability of reaching a critical, stable germ size that initiates formation of the new phase; homogeneous nucleation within a supercooled droplet is understood this way. In the singular paradigm, nucleation is determined solely by particle surface morphology; once a characteristic threshold temperature or supersaturation is acquired, ice nucleates.

Parameterizations of heterogeneous ice nucleation calculate the heterogeneously formed ice crystal number, $N_{\mathrm{i} \text {,het }}$, as a function of thermodynamic conditions and precursor aerosol properties. These parameterizations, termed INP spectra hereafter, may be empirically or theoretically based. Empirical spectra use lab or field data to calculate an active site density. Theoretically based spectra use classical nucleation theory (CNT) and calculate a nucleation rate proportional to the aerosol surface area (e.g., Karcher and Lohmann, 2002; Liu and Penner, 2005; Niemand et al., 2012; Barahona and Nenes, 2009b; Marcolli et al., 2007). The surface heterogeneity should also be considered and has recently been represented as a distribution of contact angles (Savre et al., 2013; Wang et al., 2014). But ice nucleation data is geographically or thermodynamically limited, taken only in localized regions or over a narrow range of temperatures and pressures. And classical nucleation theory is approximate and requires unknown or variable surface property data. As a result, the output of INP spectra has remained uncertain, with up to 3 orders of magnitude difference in calculated $N_{\mathrm{i}}$ (e.g., Barahona et al., 2010).

Early published INP spectra expressed active site density as a function of only temperature or supersaturation and neglected the aerosol composition and size. For example, Fletcher 1969 proposed a parameterization based solely on temperature, valid down to about $-25^{\circ} \mathrm{C}$. The Meyers et al. (1992) INP spectrum describes deposition and condensation nucleation as a function of supersaturation only, with data from a continuous-flow diffusion chamber. They observed a logarithmic increase in the number of ice-nucleating aerosol with supersaturation with respect to ice, $s_{\mathrm{i}}$.

More recently published INP spectra consider the effects of size distribution and composition of ice-nucleating particles. For example, Phillips et al. (PDA08) calculates the active site density for mineral dust, black carbon and hydrophobic organics, constrained with data from the First and Second Ice Nuclei Spectroscopy Studies (INSPECT-1 and -2) and the Cirrus Regional Study of Tropical Anvils and Cirrus Layers - Florida-Area Cirrus Experiment (CRYSTALFACE) (Phillips et al., 2008). Updates have been made in the Phillips et al. spectrum (Phillips et al., 2013; PDA13). PDA08 and PDA13 are based on the singular paradigm, in which each aerosol type nucleates ice at threshold temperatures and supersaturations. Several other studies have parameterized nucleation efficiency of mineral dusts or illite powders, using cloud chamber data or optical microscopy (e.g., Connolly et al., 2009; Niedermeier et al., 2010; Broadley et al., 2012; Niemand et al., 2012). Hiranuma et al. have also developed an INP spectrum at cirrus-relevant temperatures, using the Aerosol Interaction and Dynamics in the Atmosphere (AIDA) cloud chamber data for hematite particles (Hiranuma et al., 2014). This study uses the three aforementioned spectra to describe deposition nucleation. Other empirical spectra and recent heterogeneous ice nucleation experiments are further discussed in the review by Hoose and Möhler (2012).

Numerous studies have examined the impact of INP spectrum on nucleated ice crystal number. Using the NCAR Community Atmosphere Model (CAM), Xie et al. evaluated how predicted cloud type, cloud properties and radiative balance change based on the INP spectrum (Xie et al., 2013). The study uses Meyers et al. (1992) as a default spectrum compared to DeMott et al. (2010), a spectrum which links $N_{\mathrm{i}}$ with the aerosol number of diameter larger than $0.5 \mu \mathrm{m}$. The DeMott spectrum calculated a much lower $N_{\mathrm{i}}$, and hence a higher liquid water path and lower ice water path for Arctic mixed-phase clouds. Curry and Khvorostyanov have also run Meyers et al. (1992), DeMott et al. (1998), Phillips et al. (2008), and their own theoretical INP spectra with parcel model simulations over a range of thermodynamic conditions (Curry and Khvorostyanov, 2012). The authors emphasize the importance of applying empirical spectra only in their regions of validity and note that low nucleating efficiencies in PDA08 may underestimate ice crystal number. Prenni et al. noted that Meyers et al. (1992) significantly overpredicted ice water content in coupled models if aerosol were not depleted after nucleation (Prenni et al., 2007). When INP depletion was included, the predictions of water and ice in mixed-phase clouds improved considerably. Barahona et al. compared the output crystal number between PDA08, 
Meyers et al. (1992), Murray et al. (2010) and the Barahona and Nenes (2009b) CNT spectrum for both monodisperse and polydisperse aerosol (Barahona et al., 2010). They found that ice nucleation occurred more often in the competitive regime for the Meyers et al. (1992) spectrum, yielding smaller crystal numbers; however, PDA08 predicted higher crystal numbers with ice nucleation most frequently in the homogeneous regime. Similar results have also been reported for mixed-phase cloud conditions (e.g., Morales Betancourt et al., 2012).

In this work, we extend the adjoint of a cirrus formation parameterization (Sheyko et al., 2015) to perform sensitivity analysis for several heterogeneous INP spectra. Adjoints can calculate the sensitivity of a given output to all inputs more efficiently and accurately than finite difference runs, but at the expense of code development (Errico, 1997; Giering and Kaminski, 1998). Karydis et al. have constructed the adjoint model of a liquid droplet parameterization, and others have used adjoints for data assimilation, for example in the Community Multiscale Air Quality and ISORROPIA models (Hakami et al., 2007; Karydis et al., 2012; Capps et al., 2012). Here we use the adjoint approach to address the following: how and why $N_{\mathrm{i}}$ and its sensitivities change with the INP spectrum used and how sensitivities can elucidate nucleation regime and efficiency. Our focus is on spatial and temporal output variability, distinct from output uncertainty. The development of heterogeneous ice nucleation spectra reduces parameter uncertainty; once a spectrum is chosen, the question of how input variables contribute to output variability remains. We consider the latter here. Section 2 provides an overview of the nucleation parameterization, model inputs and four INP spectra used. Crystal number fields and aerosol acting as INP are presented in Sect. 3.1 and 3.2. Sensitivities of different spectra are discussed in Sect. 3.3 to 3.6, and Sect. 4 summarizes the work.

\section{Methods}

\subsection{BN parameterization}

We use the Barahona and Nenes cirrus formation parameterization (BN09) (Barahona and Nenes, 2008, 2009a, b) and its adjoint (Sheyko et al., 2015). BN09 describes the competition for water vapor between heterogeneous and homogeneous nucleation; the number of heterogeneously formed crystals, $N_{\mathrm{i} \text {,het }}$, is calculated from any of a variety of nucleation spectra, and homogeneously formed number, $N_{\mathrm{i} \text {,hom }}$, is calculated with an approximate solution to the coupled mass and energy balances of a cirrus cloud parcel. Then the total ice crystal number, $N_{\mathrm{i}}$, is the sum of the heterogeneous and homogeneous contributions (Eq. 1). When the temperature is greater than about $-38^{\circ} \mathrm{C}$, homogeneous nucleation ceases because it is kinetically unfavorable. Homogeneous nucleation is also suppressed when the number of INP ex- ceeds a certain threshold, $N_{\mathrm{lim}}$, and the maximum supersaturation that develops within the cloud parcel, $s_{\max }$, is less than the threshold for homogeneous nucleation, $s_{\text {hom }}$. In this case, $s_{\max }$ must be numerically calculated from the growth and supersaturation evolution equations.

$N_{\mathrm{i}}=\left\{\begin{array}{l}N_{\mathrm{i}, \text { hom }}+N_{\mathrm{i}, \text { het }}\left(s_{\text {hom }}\right), N_{\mathrm{i}, \text { het }}\left(s_{\text {hom }}\right)<N_{\text {lim }} \\ N_{\mathrm{i}, \text { het }}\left(s_{\text {max }}\right), N_{\mathrm{i}, \text { het }}\left(s_{\text {hom }}\right) \geq N_{\text {lim }}\end{array}\right.$

The BN parameterization make two principal assumptions: first, ice crystal growth occurs mostly in the free growth regime where new nucleation does not significantly change the parcel supersaturation; second, $N_{\mathrm{i}}$ is calculated at the maximum supersaturation rather than a supersaturation later in the freezing pulse. These assumptions lead to overestimation of $N_{\mathrm{i}}$ at lower temperatures and higher updraft velocities and underestimation of $N_{\mathrm{i}}$ at lower updrafts, when the freezing pulse is longer. For a wide range of cirrus formation conditions, however, the parameterization output matches that of a detailed parcel model to within $5 \%$. These points are discussed in Barahona and Nenes (2008).

As in Sheyko et al. (2015), the TAPENADE automatic differentiation tool was used to create an adjoint model of BN09 (ABN15 hereafter) (Hascoët and Pascual, 2004). For the finite series of operations that link $N_{\mathrm{i}}$ to the inputs in BN09, TAPENADE uses the chain rule to propagate a perturbation in the output, $\mathrm{d} N_{\mathrm{i}}$, back to differentials in the input variables. Once developed, the adjoint model saves significant computational time, relative to a finite difference method, and avoids both approximation and truncation errors. ABN15 differentiates $N_{\mathrm{i}}$ with respect to 13 input variables: temperature; updraft velocity; accumulation- and coarse-mode dust numbers and diameters; organic aerosol number and diameter; black carbon number and diameter; sulfate number and diameter; and water vapor deposition coefficient. All derivatives, along with the typical output of BN09, are evaluated at the input model state for each grid cell and time step of a GCM (global climate model) run. ABN15 is verified with centered finite difference approximations, using perturbations of $\pm 0.1 \%$ around each input for simulation-relevant thermodynamic and aerosol conditions. Such finite difference calculations require two runs for each variable, so for 13 input variables, the adjoint model saves 25 executions of the parameterization relative to typical sensitivity calculations.

\subsection{Simulation setup and spectra}

Simulation inputs are generated from the NCAR Community Atmosphere Model, version 5 (CAM5) at the $232 \mathrm{hPa}$ pressure level with 2-year spin-up and $2.5 \times 1.88^{\circ}$ resolution. The input updraft velocity from CAM 5.1 is calculated from the turbulent kinetic energy in the moist turbulence scheme

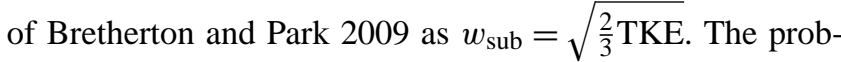
ability distribution of these values is compared to 2 years' 
worth of millimeter cloud radar measurements (MMCR) in Figs. S1 and S2 in the Supplement with all values at the same latitude, longitude and altitude. Measurements are shown after Doppler velocity decomposition, as described in Kalesse and Kollias (2013).

The distribution of hourly averaged measurements has a lower maximum and decays to smaller values than that of the hourly averaged simulation inputs. Comparing updraft distribution from aircraft and ground-based MMCR, Muhlbauer et al. (2014) note similar behavior in which the MMCR velocities were repeatedly smaller than the in situ ones; however, Muhlbauer et al. (2015) saw that lower resolution models tend to decay to even smaller values than the MMCR observations because they do not resolve the gravity wave contribution. This difference is probably due to the filtering of deep convective systems within the MMCR data but no analogous filter for simulated updrafts in this case.

We use daily averaged updraft values for which the distribution agrees better with the observed values. $w_{\text {sub }}$ values from CAM are used as the standard deviation $\sigma_{\text {sub, } w}$ of a Gaussian updraft velocity distribution $P(w)$ of mean $\mu_{\text {sub }, w}=0.1 \mathrm{~cm} \mathrm{~s}^{-1}$. Both output ice crystal numbers and sensitivities are weighted over this distribution to account for sub-grid variability (Guo et al., 2008; Morales and Nenes, 2010):

$\overline{f(w)}=\frac{\int_{0}^{\infty} f(w) P(w) \mathrm{d} w}{\int_{0}^{\infty} P(w) \mathrm{d} w}$.

This integration is performed numerically with a six-point Legendre-Gauss quadrature method, with weights and abscissae chosen over an interval from minimum to maximum velocity, which are taken as 4 standard deviations below and above $\mu_{\text {sub, } w}$. An upper bound of $3 \mathrm{~m} \mathrm{~s}^{-1}$, unlike that of $0.2 \mathrm{~m} \mathrm{~s}^{-1}$ used in Zhang et al. (2013) and Shi et al. (2015), and a lower bound of $0.001 \mathrm{~m} \mathrm{~s}^{-1}$ are enforced.

The altitude examined is in the middle of the cirrus cloud classification from the International Cloud Climatology Project (pressures between 440 and $50 \mathrm{hPa}$ ) and represents pure ice cloud formation. The Lamarque et al. emissions inventory (Lamarque et al., 2010) and MAM3 module were used (Liu et al., 2012a). Lognormal size distributions are assumed for all aerosol types with geometric standard deviations, $\sigma_{\mathrm{g}}$, assumed to be constant and listed below in Table $1 . \sigma_{\mathrm{g}}$ and total aerosol mass are used to determine geometric mean diameter for each mode. Total aerosol number is scaled by mass fraction to determine aerosol number concentrations in each mode (Morales Betancourt and Nenes, 2014). For calculations of ice crystal number concentrations and sensitivities, BN09 and ABN15 were run over a year with four heterogeneous INP spectra and daily averaged values of CAM output.

\subsection{Phillips et al. (2008, 2013) empirical spectra}

PDA08 uses the exponential correlation of crystal number and supersaturation in Meyers et al. (1992) as a reference spectrum, extending the applicable ranges of temperature and supersaturation and incorporating characteristics of the precursor aerosol. The number of ice-nucleating particles, $n_{\text {INP }, X}$ in aerosol group $X$ (dust and metallics - DM, black carbon $-\mathrm{BC}$, or organics $-\mathrm{O}$ ) is calculated with a sum over the aerosol size distribution weighted by a freezing fraction:

$$
\begin{aligned}
& n_{\mathrm{INP}, X}= \\
& \int_{\log 0.1 \mu m}^{\infty}\left\{1-\exp \left[-\mu_{X}\left(D, S_{\mathrm{i}}, T\right)\right]\right\} n_{X}(\log D) \operatorname{d} \log D .
\end{aligned}
$$

$\mu_{X}$ represents the number of ice embryos forming per aerosol and is the product of the active site density and aerosol surface area (Steinke et al., 2015): $\mu_{X}=$ $H_{X}\left(S_{\mathrm{i}}, T\right) \xi(T)\left(\frac{\alpha_{X} n_{\mathrm{INP}, *}}{\Omega_{X, *}}\right) \pi D^{2} \cdot n_{\mathrm{INP}, *}$ is the INP number from a reference activity spectrum; $\Omega_{X, *}$ is a reference aerosol surface area, which acts as a normalization factor for the size distribution; $\alpha_{X}$ is the portion of aerosol number belonging to group $X$ within $n_{\mathrm{INP}, *} ; n_{X}(\log D)$ is the aerosol size distribution; and $H_{X}$ is a threshold function that reduces INP concentrations at conditions subsaturated with respect to water and warm sub-zero temperatures in agreement with observations. $H_{X}$ equals unity at water saturation and steps at certain threshold temperatures, $T_{0, X}$, and supersaturations, $s_{\mathrm{i}, 0, X}$, for the different aerosol groups. Finally $\xi(T)$ diminishes heterogeneous nucleation at warm sub-zero temperatures.

Both PDA08 and PDA13 adopt the mathematical framework of Eq. (3), but PDA13 employs more extensive field campaign data (Phillips et al., 2013). The organic classification in PDA13 is also split into primary biological material and glassy organics, following recent observations of distinct ice-nucleating activity for these particle types. In this study, sensitivity of $N_{\mathrm{i}}$ to biological INP is not considered, as CAM5 does not currently output a biological particle number.

\subsection{Classical nucleation theory spectrum}

We also use the classical nucleation spectrum developed by Barahona and Nenes and presented in conjunction with the parameterization (Barahona and Nenes, 2009b):

$$
\begin{aligned}
& n_{\mathrm{INP}, X}= \\
& \quad e_{X} n_{X}(\log D) \min \left[\frac{s_{\mathrm{i}}}{s_{\mathrm{i}, 0, X}} e^{-f(\cos \theta) k_{\mathrm{hom}}\left(s_{\mathrm{i}, 0, X}-s_{\mathrm{i}}\right)}, 1\right],
\end{aligned}
$$

where $e_{X}$ is the nucleation efficiency of aerosol group $X, s_{i, 0, X}$ is the threshold supersaturation, $n_{X}(\log D)$ is the aerosol size distribution, $\theta$ is the INP-ice contact angle, and 
Table 1. Adjustable parameters for ABN15 simulations.

\begin{tabular}{llll}
\hline Parameter & & Value & Citation \\
\hline Pressure level & & $232 \mathrm{hPa}$ & ISCCP \\
Deposition coefficient & $\alpha$ & 0.7 & Skrotzki et al. (2013) \\
Width of BC SD & $\sigma_{\mathrm{BC}}$ & 1.8 & Dentener et al. (2006) \\
Width of dust SDs & $\sigma_{\mathrm{DM}}$ & 1.6 & d'Almeida (1987); Field et al. (2006) \\
Width of organic SD & $\sigma_{\mathrm{org}}$ & 1.8 & Dentener et al. (2006) \\
Width of sulfate SD & $\sigma_{\mathrm{sulf}}$ & 2.3 & Whitby (2007) \\
Liquid mixing ratio & $q_{c}$ & $1 \times 10^{-6} \mathrm{~kg} \mathrm{~kg}^{-1}$ & Barahona et al. (2014) \\
Surface polarity & $P_{\mathrm{S}}$ & 2 & Popovicheva et al. (2007) \\
Organic coating & $F_{\mathrm{Oc}}$ & $10 \%$ & Popovicheva et al. (2007) \\
Threshold supersaturation for dust & $s_{\mathrm{i}, 0, \mathrm{DM}}$ & $20 \%$ & Hoose and Möhler (2012) \\
Threshold supersaturation for black & $s_{\mathrm{i}, 0, \mathrm{BC}}$ & $35 \%$ & Hoose and Möhler (2012) \\
Maximum nucleation efficiency of dust & $e_{\mathrm{DM}}$ & $50 \%$ & Möhler et al. (2006) \\
Effective contact angle for dust & $\theta_{\mathrm{DM}}$ & $16^{\circ}$ & Chen et al. (2008) \\
Maximum nucleation efficiency of black carbon & $e_{\mathrm{BC}}$ & $2 \%$ & Pruppacher and Klett (1997) \\
Effective contact angle for black carbon & $\theta_{\mathrm{BC}}$ & $40^{\circ}$ & Chen et al. (2008) \\
\hline
\end{tabular}

$k_{\text {hom }}$ is a parameter related to the homogeneous nucleation threshold. Dust and black carbon groups are included with parameters listed in Table 1; contact angles come from the laboratory data of Chen et al. (2008) and $e_{\mathrm{DM}}$ is similar to that in Möhler et al. (2006). The stochastic component of the nucleation efficiency through heterogeneous nucleation rate coefficient is assumed to be negligible, and the singular paradigm also underlies this spectrum. $e_{X}$ is potentially a function of temperature and the aerosol profile, but here it is taken from literature and assumed to be constant throughout the simulation.

\subsection{Hiranuma et al. (2014) spectrum}

The nucleation efficiency of hematite particles was measured at the AIDA chamber from -78 up to $-36^{\circ} \mathrm{C}$ and parameterized (Hiranuma et al., 2014). The third-order polynomial fit for active site density (in $\mathrm{m}^{-2}$ ) is given in Eq. (5) as a function of temperature and saturation ratio of ice. Isolines from AIDA expansion cooling experiments are interpolated over the temperature-supersaturation space, assuming a hematite baseline surface area of $6.3 \times 10^{-10} \mathrm{~m}^{2} \mathrm{~L}^{-1}$.

$$
\begin{aligned}
n_{s}\left(T, S_{\mathrm{i}}\right) & =-3.777 \times 10^{13}-7.818 \times 10^{11} T+4.252 \\
& \times 10^{13} S_{\mathrm{i}}-4.598 \times 10^{9} T^{2} \\
& +6.952 \times 10^{11} T \cdot S_{\mathrm{i}}-1.111 \times 10^{13} S_{\mathrm{i}}^{2} \\
& -2.966 \times 10^{6} T^{3}+2.135 \times 10^{9} T^{2} \cdot S_{\mathrm{i}} \\
& -1.729 \times 10^{4} T \cdot S_{\mathrm{i}}^{2}-9.438 \times 10^{11} S_{\mathrm{i}}^{3}
\end{aligned}
$$

As in Hiranuma et al. (2014), we use this active site parameterization in the framework of Eq. (3) to calculate nucleated crystal number:

$$
\begin{aligned}
& n_{\mathrm{INP}, X}= \\
& \int_{\log 0.1 \mu m}^{\infty}\left\{1-\exp \left[-n_{S}\left(T, S_{\mathrm{i}}\right) \pi D^{2}\right]\right\} n_{X}(\log D) \operatorname{dlog} D .
\end{aligned}
$$

Hereafter, we refer to this formulation as the AIDA spectrum.

\section{Results}

Homogeneous and heterogeneous nucleation can be active in cirrus clouds, and their relative influence can be conceptually understood along an INP- $N_{\mathrm{i}}$ trace shown in Fig. 1a (Ren and MacKenzie, 2005; Barahona and Nenes, 2009a). When INP concentration is low, nucleation is predominantly homogeneous. The slope or sensitivity here, $\partial N_{\mathrm{i}} / \partial N_{\text {INP }}$, is slightly negative because the addition of an insoluble particle slightly decreases the number of nucleated ice crystals by competing for water vapor and decreasing supersaturation. As the INP concentration increases, homogeneous and heterogeneous nucleation compete more strongly for water vapor. Water vapor preferentially deposits on the additional INP surface and depresses the number of newly nucleated crystals, so $\partial N_{\mathrm{i}} / \partial N_{\text {INP }}$ increases in magnitude. Eventually, INP increases beyond the threshold number, $N_{\text {lim }}$, and further depletion of supersaturation inhibits homogeneous nucleation altogether. Addition of another INP increases the ice crystal number, and $\partial N_{\mathrm{i}} / \partial N_{\mathrm{INP}}$ becomes positive. While all nucleation for $N_{\text {INP }}<N_{\text {lim }}$ is competitive, we use the term "competitive nucleation" below to refer to the case when both homogeneous and heterogeneous nucleation have a significant contribution, greater than $10 \%$, to $N_{\mathrm{i}}$. These three regimes have been explained in terms of INP number, but they can also be understood in terms of INP diameter: increasing INP 

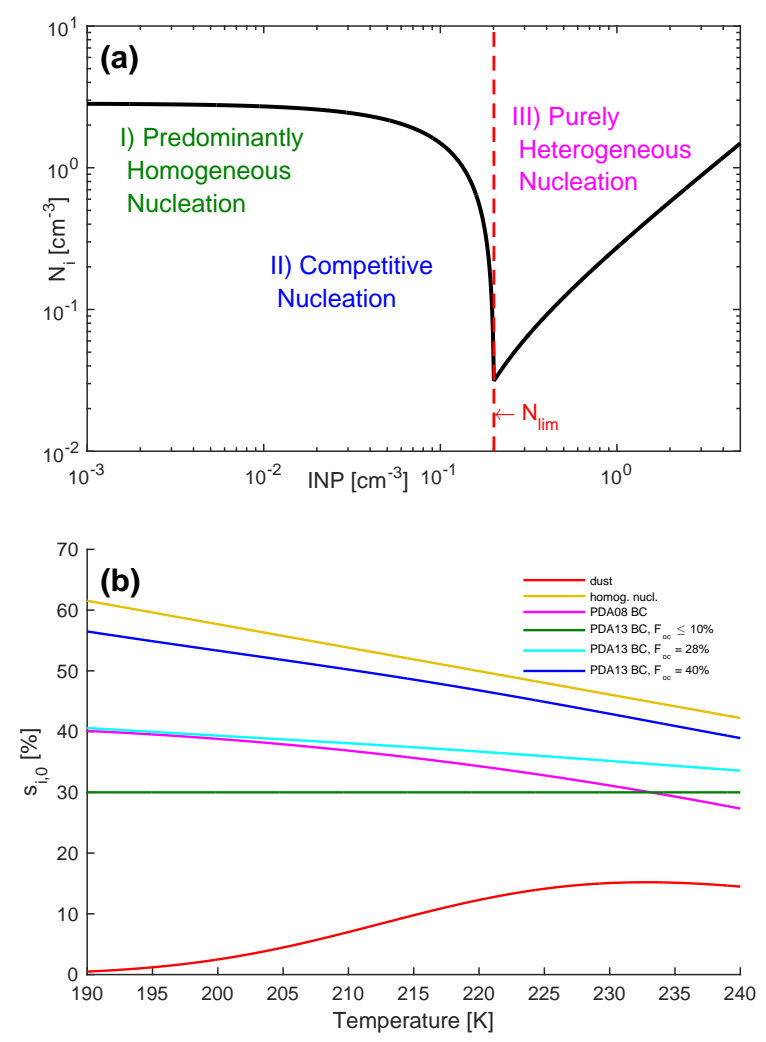

Figure 1. (a) Nucleation regimes of cirrus in the log-log INP-ice crystal number space. At low INP numbers, nucleation is predominantly homogeneous. At intermediate INP numbers, nucleation is competitive between homogeneous and heterogeneous. Beyond the threshold INP number, $N_{\text {lim }}$, nucleation is purely heterogeneous; (b) threshold supersaturations for homogeneous nucleation and heterogeneous nucleation on mineral dust and BC with different organic coatings, $F_{\mathrm{OC}}$ between 190 and $240 \mathrm{~K}$ for the PDA08 and PDA13 nucleation spectra. Both use the same correlation for dust.

surface area leads to more vapor depletion by heterogeneous nucleation and decreased crystal number in the competitive regime.

This conceptual framework is used to understand the simulation results.

\subsection{Crystal number}

Figure 2 shows a comparison of the in situ crystal number measurements, taken from the NASA MACPEX (Midlatitude Cirrus Properties Experiment) and the DOE SPARTICUS (Small Particles In Cirrus) aircraft campaigns. Data are used from the Video Ice Particle Sampler (VIPS) and two-dimensional stereo (2DS) probe during April 2011 of MACPEX and from the Forward Scattering Spectrometer Probe (FSSP) during January 2010 of SPARTICUS. Using simultaneous Meteorological Measurement System (MMS) pressure values, only $N_{\mathrm{i}}$ measurements taken within $20 \mathrm{hPa}$ of the simulated pressure level of $232 \mathrm{hPa}$ are used. Be- cause the newly nucleated ice crystal number concentration is simulated, we use only $N_{\mathrm{i}}$ from the smallest size bins of each instrument (see caption of Fig. 2). Finally, the same criterion for significant samples as in Jensen et al. (2013) is employed: samples must continuously span at least $45 \mathrm{~s}$. These MACPEX and SPARTICUS measurements, taken with shatter-resistant probes and analyzed with an inter-arrival time algorithm, are more reliable than older ones, especially for the smallest size bins that we consider (Jensen et al., 2013).

Simulated and measured $N_{\mathrm{i}}$ agree best for the PDA13 spectrum, followed by the PDA08 and then the AIDA spectra. The CNT spectrum overestimates the frequencies of $N_{\mathrm{i}}$ greater than about $10 \mathrm{~L}^{-1}$ by more than 1 order of magnitude and predicts no number concentrations less than $1 \mathrm{~L}^{-1}$. Measurements show, instead, that most of the smallest crystals occur at lower number concentrations, below about $5 \mathrm{~L}^{-1}$. The very high frequency of low $N_{\mathrm{i}}$ is missed by the other spectra as well, and all except PDA13 show slower decays in the frequency of high $N_{\mathrm{i}}$ than those in the measurements.

Model overestimate of high $N_{\mathrm{i}}$ at the coldest temperatures has been often noted (e.g., Krämer et al., 2009; Jensen et al., 2010; Barahona and Nenes, 2011). Along with this "ice nucleation puzzle" of low $N_{\mathrm{i}}$ at low temperature (Spichtinger and Krämer, 2013), model-measurement discrepancy may be explained by in-cloud processes after nucleation: nucleated crystal number will tend to be higher than in-cloud crystal number, even when looking only at the smallest size bins. Preexisting ice crystals can inhibit ice nucleation (Barahona and Nenes, 2011; Shi et al., 2015), while sedimentation can significantly reduce $N_{\mathrm{i}}$. Spichtinger and Gierens (2009) have termed the latter "sedimentation induced quenching of nucleation", and Jensen et al. (2013) found that omission of sedimentation by setting crystal fall speed to $0 \mathrm{~m} \mathrm{~s}^{-1}$ resulted in higher frequency of $N_{\mathrm{i}}$ greater than $1000 \mathrm{~L}^{-1}$.

Figure $3 \mathrm{a}$ through $\mathrm{d}$ show the annually averaged potential nucleated ice crystal number for each grid cell, given the vertical velocity and aerosol profile. The spatial variability in these fields is notable and reflects the large, documented spatial variability in INP concentrations (e.g., DeMott et al., 2010; Murray et al., 2012). Including additional microphysics after nucleation will tend to reduce this spatial variability. Some common features are still observed between fields: over the Himalayas and Rockies, $N_{\mathrm{i}}$ is higher because orographic lifting generates stronger updrafts and more supersaturation; the Saharan and Gobi desert outflows enhance $N_{\mathrm{i}, \text { het }}$; and for INP spectra considering black carbon (all except the AIDA spectrum), higher $N_{\mathrm{i}, \text { het }}$ occurs in regions of biomass burning (e.g., sub-Saharan Africa and the Amazon). In the Southern Hemisphere, especially over Antarctica, heterogeneous nucleation is rare, and $N_{\mathrm{i}}$ stays high because aerosol number concentrations are low and active site density decreases with temperature.

Elsewhere, $N_{\mathrm{i}}$ is highly variable and sensitive to the INP spectrum. For example, all spectra except PDA08 see 

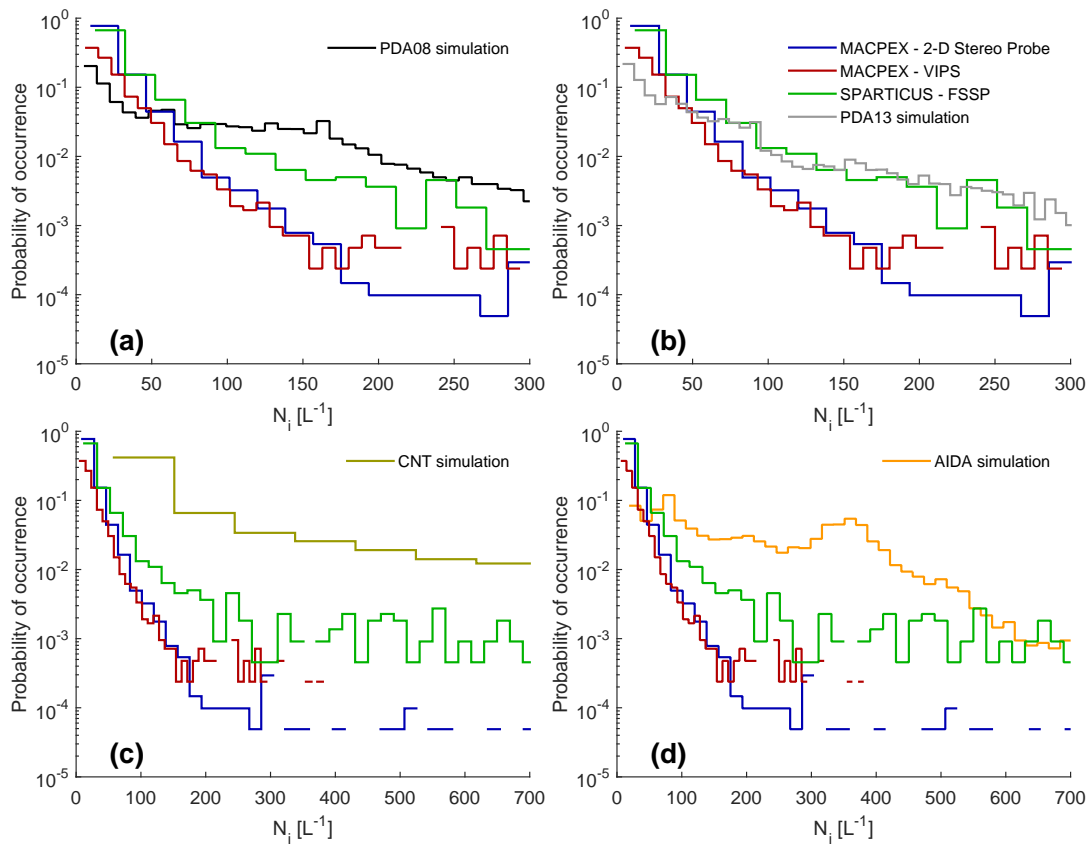

Figure 2. Measurement-model comparison of probability distributions in ice crystal number concentrations. Data distributions come from the Video Ice Particle Sampler (VIPS) and the two-dimensional stereo (2DS) probe during April 2011 of the MACPEX campaign and the Forward-Scattering Spectrometer (FSSP) during January 2010 of the SPARTICUS campaigns. Only measurements from the 10-20 $\mu$ m bin of the VIPS; the 5-15 $\mu \mathrm{m}$ bin of the 2DS; and the $0.89,1.90,3.80,5.85,8.30,11.45,14.25,17.15$ and $20.45 \mu \mathrm{m}$-centered bins of the $2 \mathrm{DS}$ are used, as approximations to the newly nucleated ice crystal number. Measurements are also filtered for altitudes of $232 \pm 20 \mathrm{hPa}$ and for uniformity, lasting at least $45 \mathrm{~s}$. Distributions of simulation output, i.e. of the annually averaged output nucleated ice crystal number, $N_{\mathrm{i}}$, as in Fig. 3, are shown using the (a) PDA08, (b) PDA13, (c) CNT and (d) AIDA nucleation spectra. Different independent axes are used in panels (c) and (d).

Table 2. Range of predicted ice-nucleating particle numbers and abundances for different nucleation spectra.

\begin{tabular}{lrrrrrr}
\hline Spectrum & $\begin{array}{r}\text { INP Range } \\
{\left[\mathrm{L}^{-1}\right]}\end{array}$ & $\begin{array}{r}\text { Median INP } \\
\text { number } \\
{\left[\mathrm{L}^{-1}\right]}\end{array}$ & $\begin{array}{r}\text { Interquartile } \\
\text { range of INP } \\
\text { number }\left[\mathrm{L}^{-1}\right]\end{array}$ & $\begin{array}{r}A_{\text {INP }} \\
\text { range }\end{array}$ & $\begin{array}{r}\text { Median } \\
A_{\text {INP }}\end{array}$ & $\begin{array}{r}\text { Interquartile } \\
\text { range of } \\
A_{\text {INP }}\end{array}$ \\
\hline PDA08 & $0.047-5.07$ & 0.48 & 1.05 & $0.0070-11.11$ & 0.34 & 0.62 \\
PDA13 & $0.57-28.6$ & 3.60 & 10.56 & $0.67-49.37$ & 10.25 & 10.02 \\
CNT & $6.94-1270.47$ & 50.38 & 169.82 & $0.97-7220.64$ & 20.80 & 36.52 \\
AIDA & $3.60-855.36$ & 52.51 & 190.49 & $4.02-4549.94$ & 20.47 & 24.35 \\
\hline
\end{tabular}

higher crystal number in the Northern Hemisphere than the Southern Hemisphere. In agreement with previous studies, PDA08 predicts the lowest INP number, between 0.047 and $5.07 \mathrm{~L}^{-1}$, (Table 2) and the highest maximum supersaturations (Barahona et al., 2010; Curry and Khvorostyanov, 2012; Morales Betancourt et al., 2012). When the input aerosol number is sufficiently high in the Northern Hemisphere, stronger competitive nucleation results in lower $N_{\mathrm{i}}$, while the Southern Hemisphere remains dominated by homogeneous nucleation and higher $N_{\mathrm{i}}$. The heterogeneously formed fraction field in Fig. S3 also illustrates these regions of competitive and homogeneous nucleation in the Northern Hemisphere $(\mathrm{NH})$ and the Southern Hemisphere $(\mathrm{SH})$, re- spectively. Updraft velocity and $N_{\mathrm{i}}$ are well-correlated; both have higher values around the equator for PDA08.

Compared to PDA08, PDA13 predicts about 1 order of magnitude higher INP number, between 0.57 and $28.6 \mathrm{~L}^{-1}$ and more frequent inhibition of homogeneous nucleation, as shown in Fig. S3, where the heterogeneously formed fraction of $N_{\mathrm{i}}$ is much higher. In localized regions of purely heterogeneous nucleation, however, PDA08 may still predict higher $N_{\mathrm{i}}$. This can be understood in terms of an INP abundance, $A_{\text {INP }} \equiv N_{\text {INP }} / N_{\text {lim }}$, defined as the ratio of available INP to the limiting number to inhibit homogeneous nucleation. $N_{\text {lim }}$ increases with decreasing maximum supersaturation, $N_{\text {lim }} \propto S_{\mathrm{i}, \max } /\left(S_{\mathrm{i}, \max }-1\right)$, and this increase in $N_{\text {lim }}$ can 

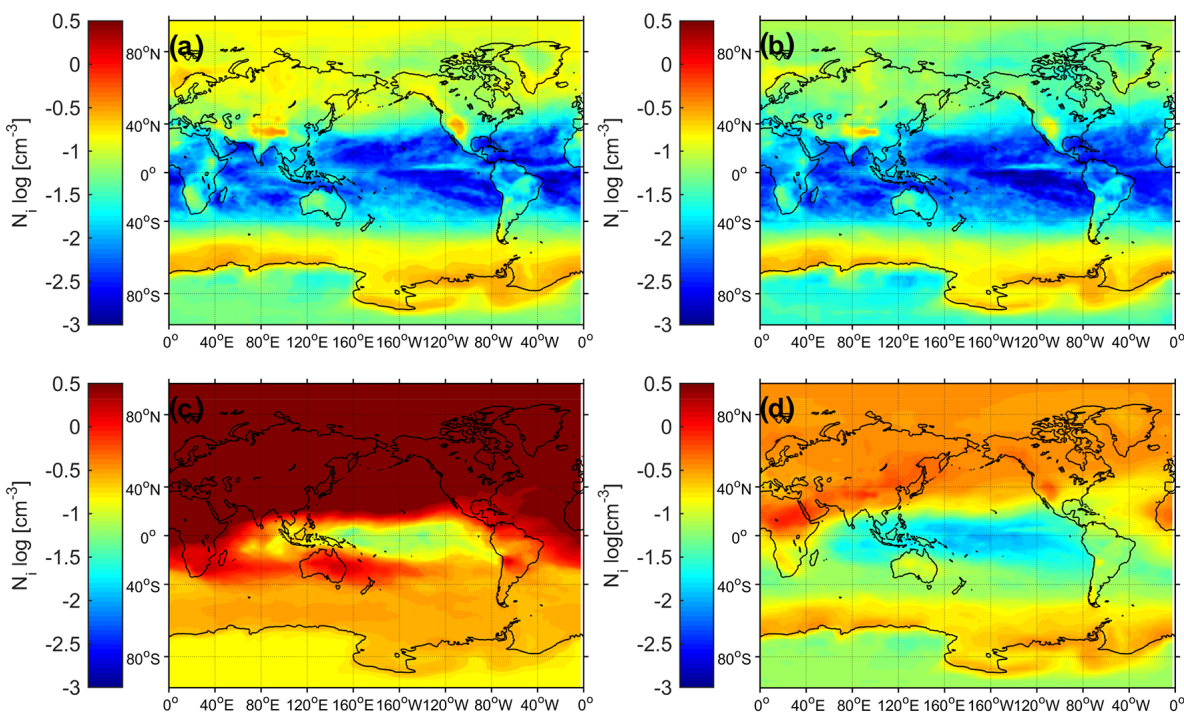

Figure 3. Annually averaged output nucleated ice crystal number, $N_{\mathrm{i}}$ from the cirrus formation parameterization for (a) PDA08, (b) PDA13, (c) CNT, (d) AIDA nucleation spectra.

outweigh the increase in INP number so that $A_{\text {INP }}$ actually decreases within PDA13.

Higher $N_{\mathrm{i}}$ in PDA08 can also be understood in terms of threshold supersaturations for nucleation, when calculated supersaturations are similar between PDA08 and PDA13. When these thresholds are less stringent, the competitive nucleation cusp of the INP- $N_{\mathrm{i}}$ trace becomes steeper and extends to lower $N_{\mathrm{i}}$ values. Where nucleation is competitive, then, as in PDA13 around the equator, very low $N_{\mathrm{i}}$ is possible.

Compared to PDA13, INP numbers in the CNT and AIDA spectra are about 10 -fold higher, with median values of 50.38 and $52.51 \mathrm{~L}^{-1}$, respectively. High INP numbers result in almost purely heterogeneous nucleation everywhere for the CNT spectrum, as shown in Fig. S3c. The highest crystal numbers in any of the fields occur for this spectrum in Saharan outflows because of the high dust nucleation efficiency and the dependence on aerosol number concentration rather than surface area here. Large accumulation-mode dust numbers can yield large $A_{\text {INP. }} N_{\mathrm{i}}$ is on the order of $1000 \mathrm{~L}^{-1}$ here, larger than any of the in situ measurements shown in Fig. 2. An overestimate of INP by CNT-based spectra has been reported elsewhere (e.g., Liu et al., 2012b).

For the AIDA spectrum, mostly heterogeneous nucleation occurs in the Northern Hemisphere, while competitive nucleation occurs in the Southern Hemisphere. INP increases lead to frequent inhibition of homogeneous ice nucleation for these last two spectra. Again, higher $N_{\mathrm{i}}$ are due to higher $A_{\text {INP }}$; here, the increase in $N_{\text {lim }}$ with decreasing supersaturation is not enough to outweigh the higher INP numbers.

A final point can be made about the strong temperature dependence of the threshold supersaturation for homogeneous nucleation. Within the CNT spectrum, the heterogeneously formed fraction of $N_{\mathrm{i}}$ actually increases in the SH (Fig. S3) because at the coldest temperatures, the threshold supersaturation for homogeneous nucleation significantly increases, as shown in Fig. 1b. A fewer number of INP are needed to depress the supersaturation enough to inhibit homogeneous nucleation; the dust INP in the CNT simulations are efficient enough to shut down homogeneous nucleation.

\subsection{Nucleating aerosol}

We consider next which aerosol groups act as INP in the regions of purely heterogeneous nucleation. For PDA08 in Fig. 4a and c, both dust and black carbon play a role. Gradients in input temperature and $\mathrm{BC}$ contribution both appear around $40^{\circ} \mathrm{S}$ because the $\mathrm{BC}$ threshold supersaturation is a quadratic function of temperature in this spectrum (Fig. 1b) (Zuberi et al., 2002). Below $60^{\circ} \mathrm{S}$, the $\mathrm{BC}$ contribution is $40 \%$ or higher for PDA08. This is unexpected because black carbon sources tend to be continental and anthropogenic, while land coverage and population density are lower in the $\mathrm{SH}$.

For PDA13, dust is by far the primary contributor to $N_{\mathrm{i} \text {,het }}$ outside of a very localized region of deep convection around the Equator. The correlation for $s_{\mathrm{i}, 0, \mathrm{DM}}$ remains the same between PDA08 and PDA13 and decreases with decreasing temperature because observations show that nucleation on dust generally becomes more efficient at colder temperatures (e.g., Möhler et al., 2006; Field et al., 2006). PDA13 also uses an updated correlation for $S_{\mathrm{i}, 0, \mathrm{BC}}$, expressed in terms of surface polarity and organic coating: 

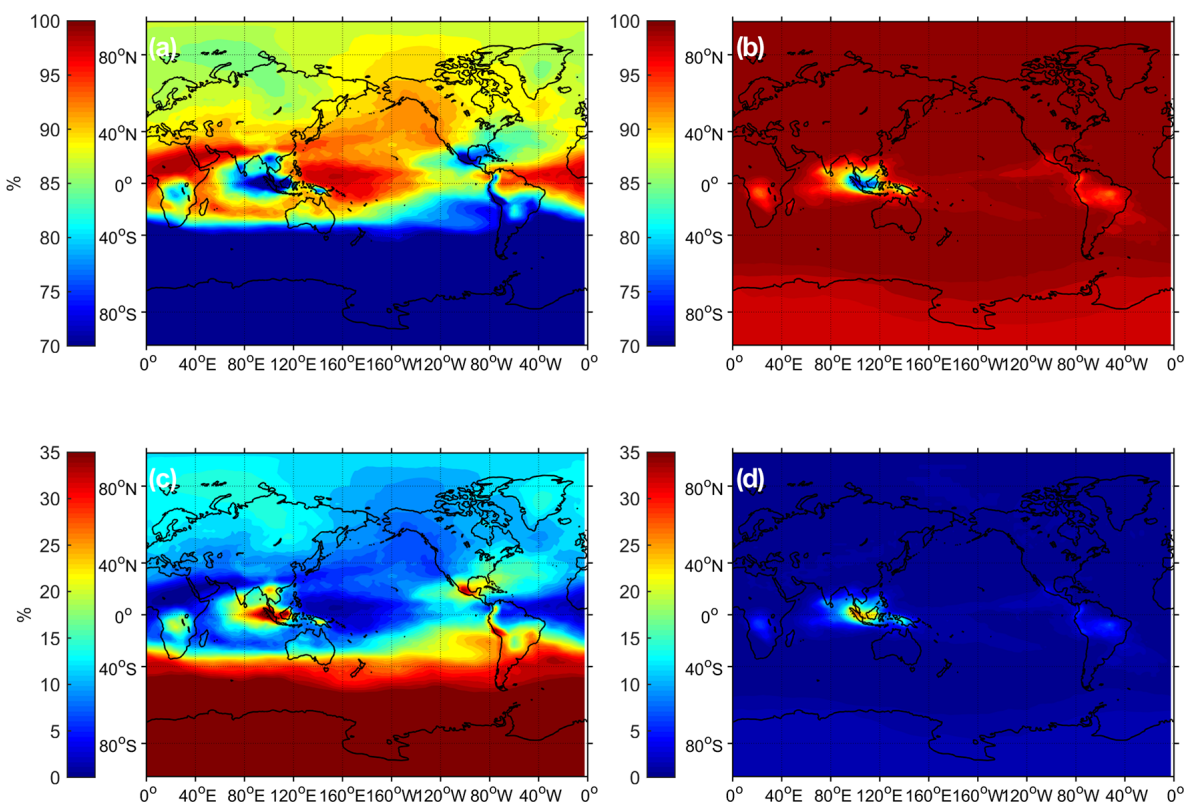

Figure 4. Annually averaged contributions of dust and BC to heterogeneously formed ice crystal number. (a) Dust contribution in PDA08; (b) dust contribution in PDA13; (c) black carbon contribution in PDA08; and (d) black carbon contribution in PDA13.

$$
\begin{aligned}
S_{\mathrm{i}, 0}^{\mathrm{BC}} & =\widetilde{S}_{i, 0}+\delta_{0}^{1}\left(F_{\mathrm{OC}}, F_{\mathrm{OC}, 0}, F_{\mathrm{OC}, 1}\right) \\
& \times\left[1.2 \times S_{\mathrm{i}}^{w}(T)-\widetilde{S}_{i, 0}\right],
\end{aligned}
$$

where $\widetilde{S}_{i, 0}$ is a baseline supersaturation of $30 \%, \delta_{0}^{1}$ is a cubic interpolation over organic coating, $F_{\mathrm{OC}}$, between lower and upper bounds of $F_{\mathrm{OC}, 0}$ and $F_{\mathrm{OC}, 1}$ (Köhler et al., 2009; Crawford et al., 2011), and $S_{\mathrm{i}}^{\mathrm{w}}$ is the saturation ratio of vapor with respect to ice at exact water saturation, since minimal nucleation has been observed at water-subsaturated conditions for heavily coated black carbon (DeMott et al., 1999). Surface polarity expresses hydrophilicity and is operationally defined as the number of water monolayers adsorbed to the aerosol surface at $50 \%$ relative humidity, while the organic coating indicates the fraction of BC surface covered in insoluble organics. These parameters are source-dependent and difficult to determine, but this study assumes a high surface polarity of two monolayers and a low organic coating of $10 \%$ to maximize any impact of black carbon (Table 1). Popovicheva et al. (2007) have also shown that these values describe aircraft engine combustion emissions, which would be relevant at this altitude.

The different aerosol contributing to INP concentrations, despite the same framework, can be understood by analyzing the expression for $\mu_{X}$. Given that the same aerosol size and number distributions have been used in both runs (Table 1), the difference is in the active site density parameterization. The observationally based terms making up the active site density are a threshold for water-subsaturated conditions, a threshold for warm sub-zero temperatures, a back- ground aerosol number, and a baseline surface area mixing ratio (Phillips et al., 2008):

$n_{S, X}=H_{X}\left(S_{\mathrm{i}}, T\right) \xi(T) \frac{\alpha_{X} n_{\mathrm{INP}, *}}{\Omega_{X, *}}$.

Between PDA08 and PDA13, the portion of aerosol belonging to the $\mathrm{BC}$ group, $\alpha_{\mathrm{BC}}$, has increased by $3 \%$, while our input temperatures are too low for the warm sub-zero temperature threshold, $\xi(T)$, to affect $N_{\text {INP }}$ calculations. The watersubsaturated threshold, $H_{X}$, would completely suppress BC nucleation if $F_{\mathrm{OC}}$ were taken to be $100 \%$; experimental evidence has shown that $\mathrm{BC}$ nucleation may only occur at water saturation when coating is significant (Möhler et al., 2006). But we have used $F_{\mathrm{OC}}$ of $10 \%$ and the threshold supersaturation has actually decreased for PDA13, as shown in Fig. 1 b. These factors alone actually yield a higher active site density for $\mathrm{BC}$ than for dust.

The difference in contributions, then, is the result of changing baseline surface area mixing ratios, $\Omega_{X, *}$. A lower active site density is needed to obtain the same freezing fraction when $\Omega_{X, *}$ is higher. Between PDA08 and PDA13, this parameter decreases 4-fold from $2 \times 10^{-6}$ to $5 \times 10^{-7} \mathrm{~m}^{2} \mathrm{~kg}^{-1}$ for dust and increases about 3-fold from $1 \times 10^{-7}$ to $2.7 \times 10^{-7} \mathrm{~m}^{2} \mathrm{~kg}^{-1}$ for BC. As a result, the freezing fraction of $\mathrm{BC}$ is much lower, even if $n_{S, \mathrm{BC}}$ is somewhat higher. Dust becomes the primary INP for PDA13 because its freezing fraction has increased. $N_{\mathrm{i}}$ from PDA13 is lower in the NH because the large dust numbers there depress $N_{\mathrm{i}, h o m}$, as shown in Figs. 3 and S3.

Surface polarity and organic coating parameters are prescribed in these simulations and may be highly variable in the 


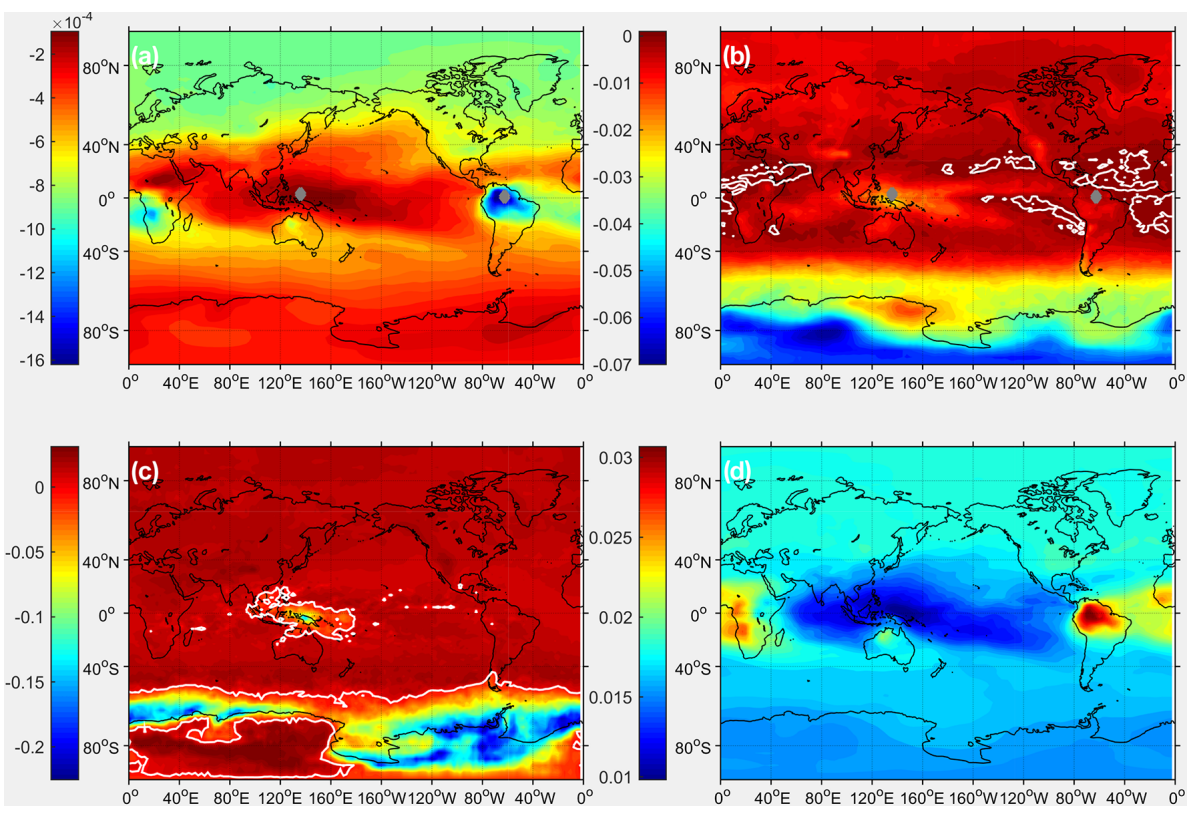

Figure 5. Annually averaged accumulation-mode dust number sensitivities for (a) PDA08, (b) PDA13, (c) CNT and (d) AIDA.

atmosphere. We have chosen a high polarity and low organic coating, so that BC contribution calculations represent an upper bound. For simulations with higher organic coatings, any INP contribution from BC disappears completely. But polarity and coating change with morphology and porosity, which change with source (Popovicheva et al., 2007). A more detailed consideration of the $\mathrm{BC}$ emissions inventory would be needed to more accurately determine these parameters and $\mathrm{BC}$ contribution to crystal number. Uncertainty also exists within the $\mathrm{BC}$ emissions inventory itself, and this, along with the coating and polarity parameters, will translate to uncertainty in the $N_{\mathrm{i}}$ field.

\subsection{Nucleation regime}

The sign and magnitude of the insoluble aerosol number sensitivities, $\partial N_{\mathrm{i}} / \partial N_{\mathrm{INP}}$, can be used to elucidate the active nucleation regime. Figure 5 gives an example with the annually averaged sensitivity of $N_{\mathrm{i}}$ to accumulation-mode dust number, $\partial N_{\mathrm{i}} / \partial N_{\text {dust,a }}$, for all spectra. In the Southern Hemisphere, sensitivities for PDA08 are of small magnitude $\left(\mathcal{O}\left(10^{-4}\right)\right)$ and negative, as homogeneous nucleation dominates. There are localized regions of strong competitive nucleation in sub-Saharan Africa and northern South America, where sensitivities are of larger magnitude $\left(\mathcal{O}\left(10^{-3}\right)\right)$ and negative. Sensitivities throughout most of the Northern Hemisphere are of moderate magnitude and negative, indicating weaker competitive nucleation.

The CNT field exhibits positive sensitivities throughout most of the Northern Hemisphere, delineated in white and indicating purely heterogeneous nucleation. PDA13 also contains regions of purely heterogeneous nucleation but around the Equator in regions of lower updraft and higher INP. When updraft velocity increases significantly - in the region of deep convection over Indonesia or over the Himalayas or Rockies due to orographic lifting - a sufficiently high supersaturation may be generated to exceed the threshold for homogeneous nucleation and induce competitive nucleation. For both the PDA13 and AIDA spectra, regions of large and negative sensitivities, or strong competitive nucleation, appear south of $60^{\circ} \mathrm{S}$. INP numbers are considerably lower than $N_{\text {lim }}$ here, but the threshold supersaturation for homogeneous nucleation has also increased at these cold temperatures.

The magnitude of negative sensitivities during competitive nucleation reflect the threshold conditions assigned to a given aerosol group. The lower the threshold supersaturation for an aerosol group, the more readily it nucleates and the more effectively it depletes water vapor; this corresponds to larger magnitude $\partial N_{\mathrm{i}} / \partial N_{\text {dust,a }}$ before $N_{\text {INP }}$ surpasses $N_{\text {lim }}$ and purely heterogeneous nucleation begins. PDA13 sensitivities to BC number are of larger magnitude than PDA08 values because $S_{\mathrm{i}, 0, \mathrm{BC}}$ is lower for the polarity and $F_{\mathrm{OC}}$ values used here. The cusp of the INP- $N_{\mathrm{i}}$ trace becomes steeper, and the competition for water vapor is stronger in this case.

$\partial N_{\mathrm{i}} / \partial N_{\text {dust,a }}$ is of large magnitude $\left(\mathcal{O}\left(10^{-2}\right)\right)$ and positive for the AIDA spectrum due to larger predicted INP numbers. These sensitivities decrease in magnitude over the Antarctic because the active site density parameterization has a strong supersaturation dependence at cold temperatures (Fig. S5). If the temperature decreases by $5 \mathrm{~K}$ for a constant supersaturation, the active site density can drop by as much as $25 \%$. The effect of this active site density parameterization on $N_{\mathrm{i}}$ is discussed further in Sect. 3.5. $\partial N_{\mathrm{i}} / \partial N_{\text {dust,a }}$ also decreases in magnitude over Indonesia because the large updrafts here 

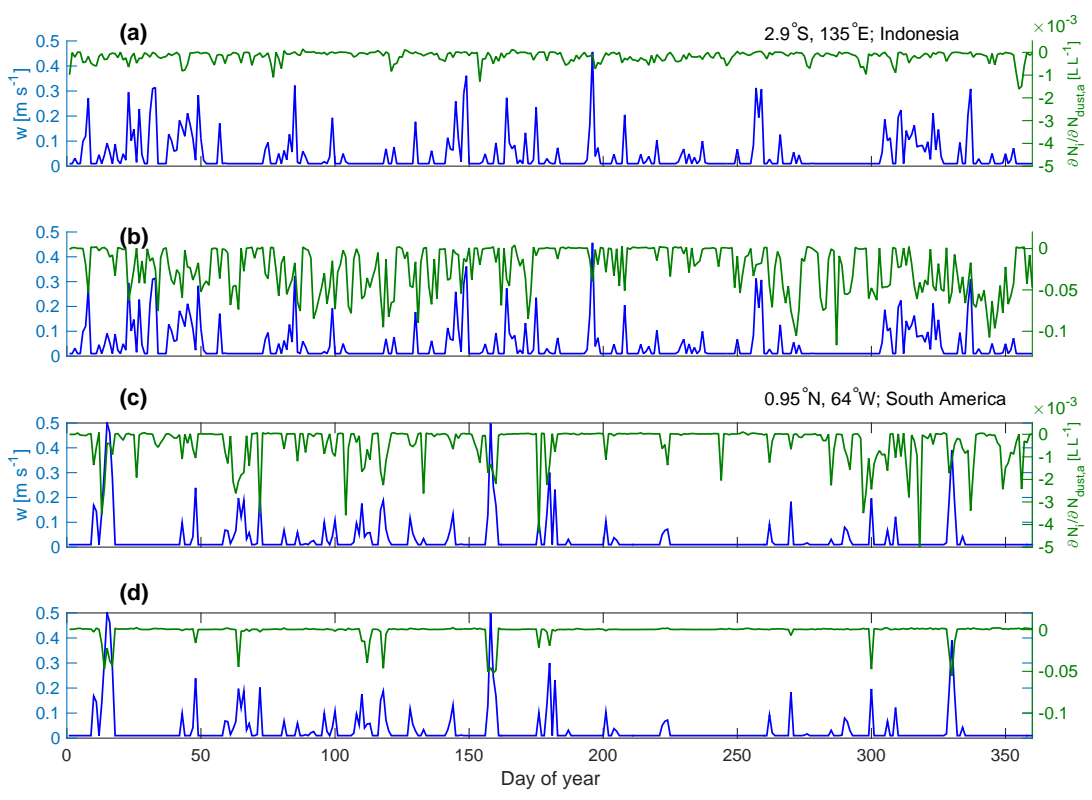

Figure 6. Time series of accumulation-mode dust number sensitivities (green, in $\mathrm{LL}^{-1}$ ) and input updraft velocities (blue, in $\mathrm{m} \mathrm{s}^{-1}$ ) over Indonesia at $2.9^{\circ} \mathrm{S}, 135^{\circ} \mathrm{E}$ for (a) PDA08 and (b) PDA13; and over South America at $0.95^{\circ} \mathrm{N}, 64^{\circ} \mathrm{W}$ for (c) PDA08 and (d) PDA13.

generate enough supersaturation that competitive nucleation occurs often and reduces the annually averaged magnitude of $\partial N_{\mathrm{i}} / \partial N_{\text {INP. }}$

Along with these spatial sensitivity patterns, we look at sensitivity time series without temporal averaging, which show the frequency of occurrence of different nucleation regimes. Infrequent but large magnitude sensitivities can have an important influence on the annual average (Sheyko et al., 2015). Distributions of both accumulation-mode dust number sensitivities and input updraft velocities are presented at $\left(2.9^{\circ} \mathrm{S}, 135^{\circ} \mathrm{E}\right)$ over Indonesia and $\left(0.95^{\circ} \mathrm{N}\right.$, $64^{\circ} \mathrm{W}$ ) over northern South America in Fig. 6. These points are denoted by diamonds in Fig. 5. Their annually averaged sensitivities differ significantly, despite their being in the same latitudinal band with similar aerosol loadings.

The location over Indonesia experiences high updraft more frequently, and the additional supersaturation generation translates to more competitive nucleation and larger magnitude sensitivities in PDA13, almost down to $-0.1 \mathrm{LL}^{-1}$. In PDA08, more supersaturation generation translates to more frequent homogeneous nucleation and smaller magnitude, less variable sensitivities, on the order of $10^{-3} \mathrm{LL}^{-1}$. The location over South America has fewer instances of high updraft, so for PDA13, the system cannot always overcome the threshold supersaturation for homogeneous nucleation. Purely heterogeneous nucleation occurs more frequently: Fig. 6d has primarily positive sensitivities of small magnitude with an occasional large spike in $\partial N_{\mathrm{i}} / \partial N_{\text {dust,a }}$, which always corresponds to a large updraft. Relative to PDA13, PDA08 exhibits stronger water vapor competition: the peaks in Fig. $6 \mathrm{c}$ are about 4 times as large as those in Fig. 6a. This behavior can be understood in terms of a transition along the INP- $N_{\mathrm{i}}$ trace in Fig. $1 \mathrm{a}: N_{\mathrm{i}}$ and $\partial N_{\mathrm{i}} / \partial N_{\text {INP }}$ respond differently to supersaturation generation based on how many INP the nucleation spectrum predicts.

\subsection{INP nucleation efficiency}

The positive values of $\partial N_{\mathrm{i}} / \partial N_{\text {INP }}$, for which nucleation is purely heterogeneous, can be understood as nucleation efficiencies: those aerosol which act as efficient INP generate a large increase in crystal number for a given increase in aerosol number. Rather than an inherent nucleation efficiency of a certain aerosol group, the sensitivity reflects an INP efficiency given the particular model state. Accumulationmode dust has a mean efficiency of $0.0012 \%\left(\mathcal{O}\left(10^{-3} \%\right)\right)$ in PDA08 and $0.079 \%(\mathcal{O}(0.1 \%))$ in PDA 13 , while coarsemode dust has a mean efficiency of $0.61 \%$ in PDA08 and $0.078 \%$ in PDA13. AIDA calculates considerably higher mean efficiency of $1.4 \%$ for the accumulation mode and $52 \%$ for the coarse mode. Black carbon in PDA08 is $0.03 \%$ efficient on average, 1 order of magnitude higher than the accumulation-mode dust. In PDA13, on the other hand, black carbon efficiency is an order lower than accumulation-mode dust and skewed toward lower values (not shown). Efficiency of organic aerosol is negligible, on the order of $10^{-5} \%$ and skewed to values as low as $10^{-12} \%$.

From Eq. (3) during purely heterogeneous nucleation,

$\frac{\partial N_{\mathrm{i}}}{\partial n_{X}}=1-\exp \left(-n_{s}\left(S_{\mathrm{i}}, T\right) \pi D^{2}\right)$.

As the number of embryos per aerosol particle becomes large, the nucleation-active fraction of the aerosol popu- 

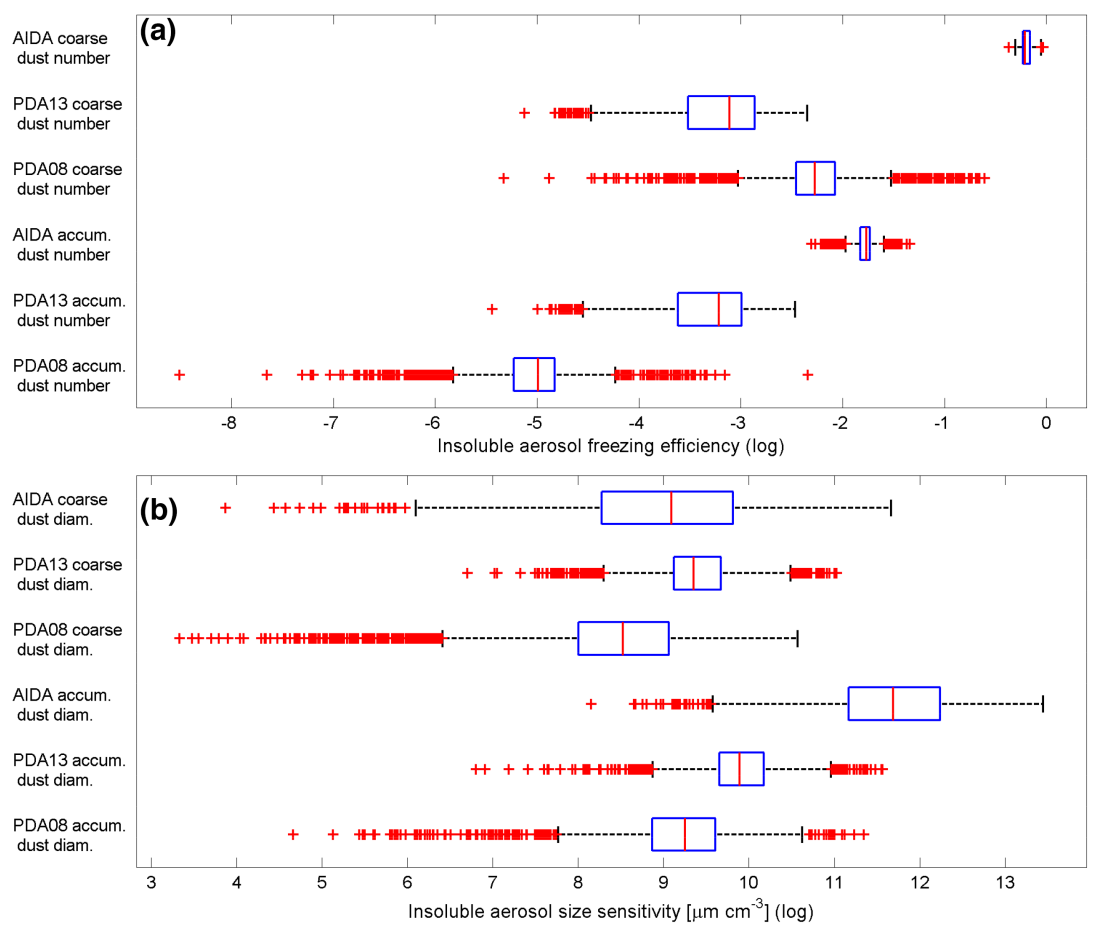

Figure 7. Log-space distributions of a random sampling of (a) accumulation- and coarse-mode dust number and (b) dust diameter for PDA08, PDA13 and AIDA spectra during purely heterogeneous nucleation. The box is constructed with 25 th percentile, $q_{1}$; median, $q_{2}$; and 75 th percentile, $q_{3}$. Outlying points are marked with crosses if they fall outside $\left[q_{1}-1.5\left(q_{3}-q_{1}\right), q_{3}+1.5\left(q_{3}-q_{1}\right)\right]$.

lation, which is equivalent to the positive aerosol number sensitivity or the nucleation efficiency, approaches unity. This occurs because the product of active site density and aerosol surface area becomes large enough that an ice embryo should always form on the INP surface. Shifts in the number sensitivities reflect changing contributions to $N_{\mathrm{i}, \text { het }}$. To illustrate, Fig. 7a shows the distribution of a random sample of 5000 daily averaged dust number sensitivities, when ice nucleation is purely heterogeneous, i.e. $\partial N_{\mathrm{i}} / \partial N_{\text {INP }}>0$. The coarse-mode dust number sensitivity is higher, and the accumulation-mode dust sensitivity is lower for PDA08 than PDA13 because BC nucleation has been suppressed in the latter. The active site density of PDA08 BC is larger than that of dust under certain conditions (Fig. S5), meaning that $\mathrm{BC}$ efficiencies are higher than the accumulation-mode dust efficiencies because aerosol diameter for the two groups is assumed to be the same. The coarse-mode sensitivities or efficiencies are even higher because their surface area is 2 orders of magnitude larger and outweighs a lower active site density.

The PDA08 distributions also have many more outliers because of the greater competition for water vapor between aerosol groups. The adjoint sensitivities are local in space and time, and in model grid cells without BC, dust in both modes is able to nucleate much more efficiently. In grid cells with more BC, the dust nucleation efficiency is significantly reduced because of the competition for water vapor between the two INP groups. The narrower range of AIDA efficiencies reinforces this point: this spectrum describes nucleation by dust in idealized conditions, and no other aerosols compete for water vapor. Its active site parameterization also contains no threshold functions that abruptly reduce nucleation. For application in global models, it may be more effective to use parameterizations from experiments with multiple nucleating aerosol types.

Once an aerosol population has reached its maximum active fraction or efficiency, $N_{\mathrm{i}}$ becomes less sensitive to the number of these aerosol. In PDA13, the coarse-mode dust population reaches an upper bound in its efficiency, and $N_{\mathrm{i}}$ sensitivity to coarse-mode number decreases to a value comparable to the accumulation-mode number. For low active fractions, Eq. (9) can be linearized so that $f_{\mathrm{IN}} \sim$ $\mathcal{O}\left(n_{s}\left(S_{\mathrm{i}}, T\right) D^{2}\right)$. Given that $n_{s} \sim \mathcal{O}\left(10^{9} \mathrm{~m}^{-2}\right)$ and $D \sim$ $\mathcal{O}\left(10^{-6} \mathrm{~m}\right)$ in the coarse mode (Fig. S5), the maximum active fraction is expected to be on the order of $10^{-3}$, which is indeed the value seen in Fig. 7.

\subsection{Size sensitivity and the active site density}

Diameter sensitivities can also be understood in terms of nucleation regime. When nucleation is purely heterogeneous, diameter sensitivity is positive; increasing aerosol diameter increases crystal number because for a given active site density, more surface area increases the number of ice embryos 
per aerosol. During competitive nucleation, diameter sensitivity becomes negative, as more available surface area for heterogeneous nucleation reduces $N_{\mathrm{i}}$ from $N_{\mathrm{i}, \mathrm{hom}}$. As with number sensitivity, the magnitude of negative diameter sensitivities reflects how intensely a certain aerosol group can deplete water vapor. The magnitude of positive diameter sensitivities is larger for coarse mode than accumulation-mode dust in all spectra (Fig. 7); an incremental increase in diameter generates more surface area for larger particles than for smaller particles.

The magnitude of positive diameter sensitivities also reflect active site density. From Eq. (3), during purely heterogeneous nucleation,

$$
\frac{\partial N_{\mathrm{i}}}{\partial D}=2 \pi D n_{X} n_{S}\left(S_{\mathrm{i}}, T\right) \exp \left(-n_{S}\left(S_{\mathrm{i}}, T\right) \pi D^{2}\right)
$$

which shows that $\partial N_{\mathrm{i}} / \partial D \propto D \exp \left(-D^{2}\right)$ and $\partial N_{\mathrm{i}} / \partial D \propto$ $n_{s} \exp \left(-n_{s}\right)$. The magnitude of diameter sensitivity first increases, then decreases, with diameter. The larger the diameter, the faster the sensitivity decreases after its maximum and the larger that maximum sensitivity. Again for active site density, the magnitude of diameter sensitivity first increases then decreases with $n_{s}$. And the larger the active site density, the faster the sensitivity decreases after reaching its maximum value. The first effect is stronger because $\partial N_{\mathrm{i}} / \partial D$ is proportional to active site density but to the square of diameter.

Figure $7 \mathrm{~b}$ is constructed again from a random sample of 5000 daily averaged dust diameter sensitivities in the purely heterogeneous regime, i.e. $\partial N_{\mathrm{i}} / \partial D_{\text {INP }}>0$. The maximum coarse-mode diameter sensitivity is smaller than that of the accumulation-mode diameter sensitivity for PDA13 and CNT because the higher number of accumulation-mode dust particles outweighs the larger coarse-mode surface area. The AIDA and PDA13 spectra tend to reach the same maximum diameter sensitivities $\left(10^{-11} \mu \mathrm{m} \mathrm{cm}^{-3}\right.$ in the coarse mode) as both have reached their maximum active fraction. These features do not characterize the PDA08 distributions because of competition for water vapor with black carbon. Given the higher active site density and equal surface area of black carbon relative to accumulation-mode dust, $\partial N_{\mathrm{i}} / \partial D_{\text {dust,a }}$ is smaller than in the other spectra. The surface area increase from the addition of a coarse-mode dust particle outweighs the higher $\mathrm{BC}$ active site density and $\partial N_{\mathrm{i}} / \partial D_{\text {dust,c }}$ in PDA08 is comparable to the values in the other spectra. In summary, spectra with large active site densities will be highly sensitive to aerosol diameter over a limited range of these diameters, while spectra with lower active site densities will be less sensitive to aerosol diameter but over a larger range of these diameters. These trends may be convoluted by competition for water vapor with other aerosol species.

\subsection{Sensitivity of $N_{\mathrm{i}}$ to temperature and sulfate aerosol}

The above discussion has focused on insoluble aerosol sensitivities. Soluble aerosol sensitivities, $\partial N_{\mathrm{i}} / \partial N_{\text {sulf }}$, are always positive because the addition of these soluble particles enhances homogeneous nucleation and crystal number, regardless of the insoluble INP profile. When purely heterogeneous nucleation occurs, $\partial N_{\mathrm{i}} / \partial N_{\text {sulf }}$ is zero. Sulfate sensitivities are generally on the order of $0.001 \mathrm{~cm}^{3} \mathrm{~cm}^{-3}$ but can be as large as $0.025 \mathrm{~cm}^{3} \mathrm{~cm}^{-3}$ at the coldest temperatures in the $\mathrm{SH}$. This field does not change in magnitude between spectra because the treatment of homogeneous nucleation is identical in all cases. $\partial N_{\mathrm{i}} / \partial N_{\text {sulf }}$ is smaller and less influential than the updraft sensitivity fields, similar to the findings of Karcher and Lohmann (2002), for which the aerosol size distribution did not strongly affect the number of nucleated ice crystals.

Temperature sensitivities, $\partial N_{\mathrm{i}} / \partial T$, are generally negative because colder temperatures tend to facilitate ice nucleation. An increase in temperature may exceed the threshold temperature for a certain aerosol group, deactivating it, and allowing homogeneous nucleation to generate a larger $N_{\mathrm{i}}$. This phenomenon can be observed in both the PDA08 and PDA13 fields, in which positive sensitivities fall exclusively at the outflow of Saharan dust around the equator where input temperature is between 225 and $230 \mathrm{~K}$. These temperatures are in the range at which the water-subsaturated threshold function for dust drops $\left(T_{0}^{\mathrm{DM}}=-40^{\circ} \mathrm{C}\right.$ and $\left.\Delta T=5^{\circ} \mathrm{C}\right)$, so that the primary contributor to heterogeneous nucleation depletes less water vapor and homogeneous nucleation yields higher $N_{\mathrm{i}}$.

The magnitude of $\partial N_{\mathrm{i}} / \partial T$ is smaller than expected from classical nucleation theory, probably due to counterbalancing effects. For example, as temperature increases so does water vapor diffusivity, which enhances crystal growth and reduces crystal number. But latent heat of sublimation also increases as temperature drops, which slows the crystal growth rate. The homogeneous nucleation coefficient increases by 1 order of magnitude with only a $30 \mathrm{~K}$ drop in temperature (Koop et al., 2000). The threshold supersaturation for dust, however, also goes down, so that deposition nucleation can more easily inhibit homogeneous nucleation. These various temperature dependencies may cancel out and lead to lower temperature sensitivities within the model. Hoose and Möhler (2012) have noted an intermediate regime in nucleation experiments for which $n_{s}$ isolines are independent of temperature and change primarily with supersaturation. Similar compensating effects, which cause low temperature sensitivity in the parameterization runs, might also explain this experimentally observed, temperature-independent regime. 


\section{Summary}

Thorough understanding of nucleated ice crystal variability in global simulations will help improve model representation of cirrus clouds and their radiative forcing. Towards this end, adjoint sensitivity analysis provides a powerful and efficient means of quantifying the prevalent ice nucleation regime, active site density and inputs driving temporal and spatial variability in the model output. From analysis of a single GCM simulation for each nucleation spectrum, using CAM 5.1 and current day emissions, we have shown the following results:

- Nucleation regime is determined by INP, but $N_{\mathrm{i}}$ is determined by threshold conditions and INP abundance. During a simulation, the number of ice-nucleating particles predicted by a nucleation spectrum determines its nucleation regime, or equivalently where the system "sits" along the INP- $N_{\mathrm{i}}$ trace. Threshold supersaturation and the number of INP relative to the limiting number determine the nucleated ice crystal number. Lower ice crystal numbers can be calculated in spite of higher INP, if certain aerosols have less stringent threshold supersaturations, because $s_{\mathrm{i}, 0, X}$ affects the steepness and depth of the competitive cusp on the INP- $N_{\mathrm{i}}$ trace. At the coldest temperatures, strong supersaturation dependence of active site parameterizations may also reduce $N_{\mathrm{i}}$. In addition, the number of INP only dictates ice crystal number relative to the limiting number to prevent homogeneous nucleation in this framework. If $N_{\text {lim }}$ calculated in one spectrum is lower relative to another, this spectrum may still calculate higher crystal number with fewer icenucleating particles.

- The baseline surface area mixing ratio, $\Omega_{X, *}$, strongly affects which INP contribute to $N_{\mathrm{i}}$. The suppression of certain INP groups manifests as a shift in the aerosol number sensitivity distributions. Dust contribution to heterogeneously formed number dominates on a global scale for PDA13 runs. Deconstructing the active site density parameterization shows that this suppression is due to a 4-fold decrease in $\Omega_{\mathrm{DM}, *}$ and 3-fold increase in $\Omega_{\mathrm{BC}, *}$, which increases the freezing fraction of dust significantly. Although the surface polarity and organic coating parameters remain unconstrained, we have chosen values which would maximize the black carbon icenucleating activity. The model predicts that black carbon contribution is negligible to $N_{\mathrm{i}}$ at this pressure level, if the PDA13 treatment is not too conservative.
Differing aerosol contributions to $N_{\mathrm{i}}$ manifest in the number sensitivity distributions. When black carbon does not act as an INP and there is no competition for water vapor between aerosol types, the sensitivity to accumulation-mode dust number increases and the sensitivity to coarse-mode dust number decreases. Glassy aerosol has a small, but regionally important and seasonally dependent contribution in PDA13 (Fig. S4).

- The sign of ice crystal number sensitivity to insoluble aerosol number or diameter indicates nucleation regime. When insoluble aerosol number or diameter sensitivities are small and negative, nucleation is predominantly homogeneous. When these values become large and negative, competitive nucleation has initiated, and when the values become positive, nucleation is purely heterogeneous. The spatial distributions of insoluble aerosol number sensitivity, as in Fig. 5, can help explain those of crystal number in Fig. 3. Temporal distributions of sensitivity can also be used to understand regime shifts along the INP- $N_{\mathrm{i}}$ trace. Spectra that predict different INP numbers may respond differently to additional supersaturation generation.

- The magnitude of positive aerosol number sensitivity reflects heterogeneous nucleation efficiency. The sensitivity of positive diameter sensitivity reflects active site density. When nucleation is purely heterogeneous, the magnitude of aerosol number sensitivity can be understood as a nucleation efficiency. The range of efficiencies is limited when there is no competition for water vapor between aerosol groups. Crystal number is more sensitive to the aerosol species with higher associated surface areas, until those species reach their maximum active fractions. In the same vein, crystal number is more sensitive to the size of larger aerosol, until the maximum active fraction is obtained. An incremental increase in the diameter of a large particle yield greater surface area but exhausts the active site density more quickly.

- Temperature sensitivities are of smaller magnitude than expected with classical nucleation theory because of compensating temperature dependencies. Limited sensitivities to temperature reflect the empirically observed "intermediate temperature regime", where supersaturation is more influential regarding nucleation. 


\section{Appendix A}

\begin{tabular}{|c|c|}
\hline BN09 & Barahona and Nenes (2009b) cirrus formation parameterization \\
\hline$N_{\mathrm{i}, \mathrm{het}}$ & Heterogeneously formed ice crystal number \\
\hline INP & Ice-nucleating particles \\
\hline$s_{\mathrm{i}}$ & Supersaturation of water vapor with respect to ice \\
\hline PDA08 & Phillips et al. (2008) INP spectrum \\
\hline PDA13 & Phillips et al. (2013) INP spectrum, updated from 2008 \\
\hline AIDA & $\begin{array}{l}\text { Heterogeneous INP spectra derived from Aerosol Interaction and Dynamics in the Atmosphere } \\
\text { cloud chamber data }\end{array}$ \\
\hline$N_{\mathrm{i}, \text { het }}$ & Number of heterogeneously nucleated ice crystals \\
\hline$N_{\mathrm{i}, \mathrm{hom}}$ & Number of homogeneously nucleated ice crystals \\
\hline$N_{\lim }$ & Limiting number of INP to prevent homogeneous nucleation \\
\hline$s_{\max }$ & Maximum supersaturation which develops within the cloud parcel \\
\hline$s_{\mathrm{hom}}$ & Threshold supersaturation for homogeneous nucleation \\
\hline$S_{\mathrm{i}}$ & Saturation ratio of water vapor with respect to ice \\
\hline$\mu_{X}$ & Number of ice embryos per aerosol surface \\
\hline$\partial N_{\mathrm{i}} / \partial D_{\text {dust.c }}$ & Nucleated ice crystal number sensitivity to coarse-mode dust diameter \\
\hline$\partial N_{\mathrm{i}} / \partial D_{\text {dust,a }}$ & Nucleated ice crystal number sensitivity to accumulation-mode dust diameter \\
\hline$\partial N_{\mathrm{i}} / \partial N_{\text {dust,c }}$ & Nucleated ice crystal number sensitivity to coarse-mode dust number \\
\hline$\partial N_{\mathrm{i}} / \partial N_{\text {dust,a }}$ & Nucleated ice crystal number sensitivity to accumulation-mode dust number \\
\hline
\end{tabular}




\section{The Supplement related to this article is available online at doi:10.5194/acp-16-2611-2016-supplement.}

Acknowledgements. This work was made possible through support from DOE EaSM. S. C. Sullivan gratefully acknowledges support from a National Aeronautics and Space Administration Earth and Space Science Fellowship. We would like to thank two anonymous reviewers for their thorough and insightful feedback, in particular for suggestions about measurement-model comparison. Data in Fig. 2 comes from Andrew Heymsfield's VIPS and Paul Lawson's TDS measurements aboard the WB57 during MACPEX and from Paul Lawson's F-FSSP measurements aboard the SPEC Learjet during SPARTICUS. Thanks also to Heike Kalesse for the use of processed vertical motion data from SPARTICUS.

Edited by: J. Quaas

\section{References}

Barahona, D.: On the ice nucleation spectrum, Atmos. Chem. Phys., 12, 3733-3752, doi:10.5194/acp-12-3733-2012, 2012.

Barahona, D. and Nenes, A.: Parameterization of cirrus cloud formation in large-scale models: Homogeneous nucleation, J. Geophys. Res., 113, D11211, doi:10.1029/2007JD009355, 2008.

Barahona, D. and Nenes, A.: Parameterizing the competition between homogeneous and heterogeneous freezing in cirrus cloud formation - monodisperse ice nuclei, Atmos. Chem. Phys., 9, 369-381, doi:10.5194/acp-9-369-2009, 2009a.

Barahona, D. and Nenes, A.: Parameterizing the competition between homogeneous and heterogeneous freezing in ice cloud formation - polydisperse ice nuclei, Atmos. Chem. Phys., 9, 59335948, doi:10.5194/acp-9-5933-2009, 2009b.

Barahona, D. and Nenes, A.: Dynamical states of low temperature cirrus, Atmos. Chem. Phys., 11, 3757-3771, doi:10.5194/acp11-3757-2011, 2011.

Barahona, D., Rodriguez, J., and Nenes, A.: Sensitivity of the global distribution of cirrus ice crystal concentration to heterogeneous freezing, J. Geoph. Res., 115, D23213, doi:10.1029/2010JD014273, 2010.

Barahona, D., Molod, A., Bacmeister, J., Nenes, A., Gettelman, A., Morrison, H., Phillips, V., and Eichmann, A.: Development of two-moment cloud microphysics for liquid and ice within the NASA Goddard Earth Observing System Model (GEOS-5), Geosci. Model Dev., 7, 1733-1766, doi:10.5194/gmd-7-17332014, 2014.

Boucher, O., Randall, D., Artaxo, P., Bretherton, C., Feingold, G., Forster, P., Kerminen, V.-M., Kondo, Y., Liao, H., Lohmann, U., Rasch, P., Sathessh, S., Sherwood, S., Stevens, B., and Zhang, X.: Clouds and Aerosols, in: Climate Change 2013: The Physical Science Basis. Contribution of Working Group I to the Fifth Assessment Report of the Intergovernmental Panel on Climate Change, Cambridge University Press, 2013.

Brewer, J.: Evidence for a world circulation provided by the measurements of helium and water vapour distribution in the stratosphere, Q. J. Roy. Meteor. Soc., 75, 351-363, doi:10.1002/qj.49707532603, 1949.
Broadley, S. L., Murray, B. J., Herbert, R. J., Atkinson, J. D., Dobbie, S., Malkin, T. L., Condliffe, E., and Neve, L.: Immersion mode heterogeneous ice nucleation by an illite rich powder representative of atmospheric mineral dust, Atmos. Chem. Phys., 12, 287-307, doi:10.5194/acp-12-287-2012, 2012.

Capps, S. L., Henze, D. K., Hakami, A., Russell, A. G., and Nenes, A.: ANISORROPIA: the adjoint of the aerosol thermodynamic model ISORROPIA, Atmos. Chem. Phys., 12, 527-543, doi:10.5194/acp-12-527-2012, 2012.

Chen, J.-P., Hazra, A., and Levin, Z.: Parameterizing ice nucleation rates using contact angle and activation energy derived from laboratory data, Atmos. Chem. Phys., 8, 7431-7449, doi:10.5194/acp-8-7431-2008, 2008.

Chen, T., Rossow, W. B., and Zhang, Y.: Radiative effects of cloudtype variations, J. Climate, 13, 264-286, doi:10.1175/15200442(2000)013<0264:REOCTV>2.0.CO;2, 2000.

Connolly, P. J., Möhler, O., Field, P. R., Saathoff, H., Burgess, R., Choularton, T., and Gallagher, M.: Studies of heterogeneous freezing by three different desert dust samples, Atmos. Chem. Phys., 9, 2805-2824, doi:10.5194/acp-9-2805-2009, 2009.

Cox, S. J., Kathmann, S. M., Slater, B., and Michaelides, A.: Molecular simulations of heterogeneous ice nucleation. I. Controlling ice nucleation through surface hydrophilicity, J. Chem. Phys., 142, 184704, doi:10.1063/1.4919714, 2015.

Crawford, I., Möhler, O., Schnaiter, M., Saathoff, H., Liu, D., McMeeking, G., Linke, C., Flynn, M., Bower, K. N., Connolly, P. J., Gallagher, M. W., and Coe, H.: Studies of propane flame soot acting as heterogeneous ice nuclei in conjunction with single particle soot photometer measurements, Atmos. Chem. Phys., 11, 9549-9561, doi:10.5194/acp-11-9549-2011, 2011.

Curry, J. A. and Khvorostyanov, V. I.: Assessment of some parameterizations of heterogeneous ice nucleation in cloud and climate models, Atmos. Chem. Phys., 12, 1151-1172, doi:10.5194/acp12-1151-2012, 2012.

Cziczo, D., Froyd, K., Hoose, C., Jensen, E., Diao, M., Zondlo, M., Smith, J., Twohy, C., and Murphy, D.: Clarifying the dominant sources and mechanisms of cirrus cloud formation, Science, 340, 1320-1324, doi:10.1126/science.1234145, 2013.

d'Almeida, G.: On the variability of desert aerosol radiative characteristics, J. Geophys. Res., 92, 3017-3026, doi:10.1029/JD092iD03p03017, 1987.

DeMott, P. J., Rogers, D. C., Kreidenweis, S. M., Chen, Y., Twohy, C. H., Baumgardner, D., Heymsfield A. J., and Chan, K. R.: The role of heterogeneous freezing nucleation in upper tropospheric clouds: Inferences from SUCCESS, Geophys. Res. Lett., 25, 1387-1390, 1998.

DeMott, P., Chen, Y., Kreidenweis, S., Rogers, D., and Sherman, D.: Ice formation by black carbon particles, Geophys. Res. Lett., 26, 2429-2432, doi:10.1029/1999GL900580, 1999.

DeMott, P. J., Prenni, A. J., Liu, X., Kreidenweis, S. M., Petters, M. D., Twohy, C. H., Richardson, M. S., Eidhammer, T., and Rogers, D. C.: Predicting global atmospheric ice nuclei distributions and their impacts on climate, P. Natl. Acad. Sci., 107, 11217-11222, doi:10.1073/pnas.0910818107, 2010.

Dentener, F., Kinne, S., Bond, T., Boucher, O., Cofala, J., Generoso, S., Ginoux, P., Gong, S., Hoelzemann, J. J., Ito, A., Marelli, L., Penner, J. E., Putaud, J.-P., Textor, C., Schulz, M., van der Werf, G. R., and Wilson, J.: Emissions of primary aerosol and precursor gases in the years 2000 and 1750 prescribed data-sets for Ae- 
roCom, Atmos. Chem. Phys., 6, 4321-4344, doi:10.5194/acp-64321-2006, 2006.

Errico, R. M.: What is an adjoint model?, B. Am. Meterol. Soc., 78, 2577-2591, doi:10.1175/15200477(1997)<2577:WIAAM>2.0.CO;2, 1997.

Field, P. R., Möhler, O., Connolly, P., Krämer, M., Cotton, R., Heymsfield, A. J., Saathoff, H., and Schnaiter, M.: Some ice nucleation characteristics of Asian and Saharan desert dust, Atmos. Chem. Phys., 6, 2991-3006, doi:10.5194/acp-6-2991-2006, 2006.

Giering, R. and Kaminski, T.: Recipes for Adjoint Code Construction, ACM Trans. Mathematical Software, 24, 437-474, doi:10.1145/293686.293695, 1998.

Guo, H., Liu, Y., Daum, P., Senum, G., and Tao, W.-K.: Characteristics of vertical velocity in marine stratocumulus: comparison of large eddy simulations with observations, Environ. Res. Lett., 3, 045020, doi:10.1088/1748-9326/3/4/045020, 2008.

Hakami, A., Henze, D., Seinfeld, J., Singh, K., Sandu, A., Kim, S., Byun, D., and Li, Q.: The Adjoint of CMAQ, Environ. Sci. Technol., 41, 7807-7817, doi:10.1021/es070944p, 2007.

Hascoët, L. and Pascual, V.: TAPENADE 2.1 user's guide, INRIA Technical Report RT-0300, p. 78, 2004.

Hiranuma, N., Hoffmann, N., Kiselev, A., Dreyer, A., Zhang, K., Kulkarni, G., Koop, T., and Möhler, O.: Influence of surface morphology on the immersion mode ice nucleation efficiency of hematite particles, Atmos. Chem. Phys., 14, 2315-2324, doi:10.5194/acp-14-2315-2014, 2014..

Hoose, C. and Möhler, O.: Heterogeneous ice nucleation on atmospheric aerosols: a review of results from laboratory experiments, Atmos. Chem. Phys., 12, 9817-9854, doi:10.5194/acp-12-98172012, 2012.

Jensen, E. J., Kinne, S., and Toon, O. B.: Tropical cirrus cloud radiative forcing - sensitivity studies, Geophys. Res. Lett., 21, 2023 2026, doi:10.1029/94GL01358, 1994.

Jensen, E. J., Pfister, L., Bui, T.-P., Lawson, P., and Baumgardner, D.: Ice nucleation and cloud microphysical properties in tropical tropopause layer cirrus, Atmos. Chem. Phys., 10, 1369-1384, doi:10.5194/acp-10-1369-2010, 2010.

Jensen, E. J., Lawson, R. P., Bergman, J. W., Pfister, L., Bui, T. P., and Schmitt, C. G.: Physical processes controlling ice concentrations in synoptically forced, midlatitude cirrus, J. Geophys. Res., 118, 5348-5360, doi:10.1002/jgrd.50421, 2013.

Kalesse, H. and Kollias, P.: Climatology of high cloud dynamics using profiling ARM Doppler Radar observations, J. Climate, 26, 6340-6359, doi:10.1175/JCLI-D-12-00695.1, 2013.

Karcher, B. and Lohmann, U.: A Parameterization of cirrus cloud formation: Homogeneous freezing including effects of aerosol size, J. Geophys. Res., 107, 4698, doi:10.1029/2001JD001429, 2002.

Karydis, V. A., Capps, S. L., Russell, A. G., and Nenes, A.: Adjoint sensitivity of global cloud droplet number to aerosol and dynamical parameters, Atmos. Chem. Phys., 12, 9041-9055, doi:10.5194/acp-12-9041-2012, 2012.

Köhler, K. A., DeMott, P. J., Kreidenweis, S. M., Popovicheva, O. B., Petters, M. D., Carrico, C. M., Kireeva, E. D., Khokhlova, T. D., and Shonija, N. K.: Cloud condensation nuclei and ice nucleation activity of hydrophobic and hydrophilic soot particles, Phys. Chem. Chem. Phys., 11, 79067920, doi:10.1039/B905334B, 2009.
Koop, T., Luo, B., Tsias, A., and Peter, T.: Water activity as the determinant for homogeneous ice nucleation in aqueous solutions, Nature, 406, 611-614, doi:10.1038/35020537, 2000.

Krämer, M., Schiller, C., Afchine, A., Bauer, R., Gensch, I., Mangold, A., Schlicht, S., Spelten, N., Sitnikov, N., Borrmann, S., de Reus, M., and Spichtinger, P.: Ice supersaturations and cirrus cloud crystal numbers, Atmos. Chem. Phys., 9, 3505-3522, doi:10.5194/acp-9-3505-2009, 2009.

Kulkarni, G., Fan, J., Comstock, J. M., Liu, X., and Ovchinnikov, M.: Laboratory measurements and model sensitivity studies of dust deposition ice nucleation, Atmos. Chem. Phys., 12, 72957308, doi:10.5194/acp-12-7295-2012, 2012.

Lamarque, J.-F., Bond, T. C., Eyring, V., Granier, C., Heil, A., Klimont, Z., Lee, D., Liousse, C., Mieville, A., Owen, B., Schultz, M. G., Shindell, D., Smith, S. J., Stehfest, E., Van Aardenne, J., Cooper, O. R., Kainuma, M., Mahowald, N., McConnell, J. R., Naik, V., Riahi, K., and van Vuuren, D. P.: Historical (1850-2000) gridded anthropogenic and biomass burning emissions of reactive gases and aerosols: methodology and application, Atmos. Chem. Phys., 10, 7017-7039, doi:10.5194/acp10-7017-2010, 2010.

Lin, R.-F., Starr, D. O., Reichardt, J., and DeMott, P. J.: Nucleation in synoptically forced cirrostratus, J. Geophys. Res., 110, D08208, doi:10.1029/2004JD005362, 2005.

Liu, X. and Penner, J.: Ice nucleation parameterization for global models, Met. Zeit., 14, 499-514, doi:10.1127/09412948/2005/0059, 2005.

Liu, X., Easter, R. C., Ghan, S. J., Zaveri, R., Rasch, P., Shi, X., Lamarque, J.-F., Gettelman, A., Morrison, H., Vitt, F., Conley, A., Park, S., Neale, R., Hannay, C., Ekman, A. M. L., Hess, P., Mahowald, N., Collins, W., Iacono, M. J., Bretherton, C. S., Flanner, M. G., and Mitchell, D.: Toward a minimal representation of aerosols in climate models: description and evaluation in the Community Atmosphere Model CAM5, Geosci. Model Dev., 5, 709-739, doi:10.5194/gmd-5-709-2012, 2012a.

Liu, X., Shi, X., Zhang, K., Jensen, E. J., Gettelman, A., Barahona, D., Nenes, A., and Lawson, P.: Sensitivity studies of dust ice nuclei effect on cirrus clouds with the Community Atmosphere Model CAM5, Atmos. Chem. Phys., 12, 12061-12079, doi:10.5194/acp-12-12061-2012, 2012b.

Lupi, L., Hudait, A., and Molinero, V.: Heterogeneous Nucleation of Ice on Carbon Surfaces, J. Am. Chem. Soc., 136, 3156-3164, doi:10.1021/ja411507a, 2014.

Marcolli, C., Gedamke, S., Peter, T., and Zobrist, B.: Efficiency of immersion mode ice nucleation on surrogates of mineral dust, Atmos. Chem. Phys., 7, 5081-5091, doi:10.5194/acp-7-50812007, 2007.

Meyers, M., DeMott, P., and Cotton, R.: New primary icenucleation parameterization in an explicit cloud model, J. Appl. Meteorol., 31, 708-721, doi:10.1175/15200450(1992)031<0708:NPINPI>2.0.CO;2, 1992.

Möhler, O., Field, P. R., Connolly, P., Benz, S., Saathoff, H., Schnaiter, M., Wagner, R., Cotton, R., Krämer, M., Mangold, A., and Heymsfield, A. J.: Efficiency of the deposition mode ice nucleation on mineral dust particles, Atmos. Chem. Phys., 6, 30073021, doi:10.5194/acp-6-3007-2006, 2006. 
Morales, R. and Nenes, A.: Characteristic updrafts for computing distribution-averaged cloud droplet number and stratocumulus cloud properties, J. Geophys. Res., 115, D18220, doi:10.1029/2009JD013233, 2010.

Morales Betancourt, R. and Nenes, A.: Understanding the contributions of aerosol properties and parameterization discrepancies to droplet number variability in a global climate model, Atmos. Chem. Phys., 14, 4809-4826, doi:10.5194/acp-14-48092014, 2014.

Morales Betancourt, R., Lee, D., Oreopoulos, L., Sud, Y. C., Barahona, D., and Nenes, A.: Sensitivity of cirrus and mixed-phase clouds to the ice nuclei spectra in McRAS-AC: single column model simulations, Atmos. Chem. Phys., 12, 10679-10692, doi:10.5194/acp-12-10679-2012, 2012.

Muhlbauer, A., Kalesse, H., and Kollias, P.: Vertical velocities and turbulence in midlatitude anvil cirrus: A comparison between in situ aircraft measurements and ground-based Doppler cloud radar retrievals, Geophys. Res. Lett., 41, 7814-7821, doi:10.1002/2014GL062279, 2014.

Muhlbauer, A., Ackerman, T. P., Lawson, R. P., Xie, S., and Zhang, Y.: Evaluation of cloud-resolving model simulations of midlatitude cirrus with ARM and A-train observations, J. Geophys. Res., 120, 6597-6618, doi:10.1002/2014JD022570, 2015.

Murray, B. J., Wilson, T. W., Dobbie, S., Cui, Z., Al-Jumur S. M. R. K., Möhler, O., Schnaiter M., Wagner R., Benz S., Niemand, M., Saathoff, H., Ebert, V., Wagner, S., and Kärcher, B.: Heterogeneous nucleation of ice particles on glassy aerosol under cirrus conditions, Nat. Geosci., 3, 233-237, 2010.

Murray, B., O'Sullivan, D., Atkinson, J., and Webb, M.: Ice nucleation by particles immersed in supercooled cloud droplets, Chem. Soc. Rev., 41, 6519-6554, doi:10.1039/c2cs35200a, 2012.

Niedermeier, D., Hartmann, S., Shaw, R. A., Covert, D., Mentel, T. F., Schneider, J., Poulain, L., Reitz, P., Spindler, C., Clauss, T., Kiselev, A., Hallbauer, E., Wex, H., Mildenberger, K., and Stratmann, F.: Heterogeneous freezing of droplets with immersed mineral dust particles - measurements and parameterization, Atmos. Chem. Phys., 10, 3601-3614, doi:10.5194/acp-10-36012010, 2010.

Niemand, M., Möhler, O., Vogel, B., Vogel, H., and Hoose, C.: A particle-surface-area-based parameterization of immersion freezing on desert dust particles, J. Atmos. Sci., 69, 3077-3092, doi:10.1175/JAS-D-11-0249.1, 2012.

Phillips, V., DeMott, P., and Andronache, C.: An empirical parameterization of heterogeneous ice nucleation for multiple chemical species of aerosol, J. Atmos. Sci., 65, 2757-2783, doi:10.1175/2007JAS2546.1, 2008.

Phillips, V., DeMott, P., Andronache, C., Pratt, K., Prather, K., Subramanian, R., and Twohy, C.: Improvements to an empirical parameterization of heterogeneous ice nucleation and its comparison with observations, J. Atmos. Sci., 70, 378-409, doi:10.1175/JAS-D-12-080.1, 2013.

Popovicheva, O., Persiantseva, N., Shonija, N., DeMott, P., Koehler, K., Petters, M., Kreidenweis, S., Tishkova, V., Demirdjian, B., and Suzanne, J.: Water interaction with hydrophobic and hydrophilic soot particles, Phys. Chem. Chem. Phys., 10, 23322344, doi:10.1039/b718944n, 2007.
Prenni, A., Harrington, J., Tjernström, M., DeMott, P., Avramov, A., Long, C., Kreidenweis, S., Olsson, P., and Verlinde, J.: Can Ice-Nucleating Aerosols Affect Arctic Seasonal Climate?, B. Am. Meteorol. Soc., 88, 541-550, doi:10.1175/BAMS-88-4-541, 2007.

Pruppacher, H. and Klett, J.: Microphysics of clouds and precipitation, 2nd Edn., Kluwer Academic Publishers, Boston, MA, 1997.

Reinhardt, A. and Doye, J. P. K.: Effects of surface interactions on heterogeneous ice nucleation for a monatomic water model, J. Chem. Phys., 141, 084501, doi:10.1063/1.4892804, 2014.

Ren, C. and MacKenzie, A.: Cirrus parameterization and the role of ice nuclei, Q. J. Roy. Meteor. Soc., 131, 1585-1605, doi:10.1256/qj.04.126, 2005.

Savre, J., Ekman, A., Svensson, G., and Tjernström, M.: Parameterizing ice nucleation ability of mineral dust particles in the deposition mode: numerical investigations using large eddy simulation, AIP Proceedings, 1527, 922, doi:10.1063/1.4803422, 2013.

Sheyko, B., Sullivan, S. C., Morales-Betancourt, R., Capps, S., Barahona, D., Shi, X., Liu, X., and Nenes, A.: Quantifying sensitivities of ice crystal number and sources of ice crystal number variability in CAM 5.1 using the adjoint of a physically based cirrus formation parameterization, J. Geophys. Res., 120, 2834 2854, doi:10.1002/2014JD022457, 2015.

Shi, X., Liu, X., and Zhang, K.: Effects of pre-existing ice crystals on cirrus clouds and comparison between different ice nucleation parameterizations with the Community Atmosphere Model (CAM5), Atmos. Chem. Phys., 15, 1503-1520, doi:10.5194/acp15-1503-2015, 2015.

Skrotzki, J., Connolly, P., Schnaiter, M., Saathoff, H., Möhler, O., Wagner, R., Niemand, M., Ebert, V., and Leisner, T.: The accommodation coefficient of water molecules on ice - cirrus cloud studies at the AIDA simulation chamber, Atmos. Chem. Phys., 13, 4451-4466, doi:10.5194/acp-13-4451-2013, 2013.

Spichtinger, P. and Gierens, K. M.: Modelling of cirrus clouds - Part 1 b: Structuring cirrus clouds by dynamics, Atmos. Chem. Phys., 9, 707-719, doi:10.5194/acp-9-707-2009, 2009.

Spichtinger, P. and Krämer, M.: Tropical tropopause ice clouds: a dynamic approach to the mystery of low crystal numbers, Atmos. Chem. Phys., 13, 9801-9818, doi:10.5194/acp-13-98012013, 2013.

Steinke, I., Hoose, C., Möhler, O., Connolly, P., and Leisner, T.: A new temperature- and humidity-dependent surface site density approach for deposition ice nucleation, Atmos. Chem. Phys., 15, 3703-3717, doi:10.5194/acp-15-3703-2015, 2015.

Vali, G.: Interpretation of freezing nucleation experiments: singular and stochastic; sites and surfaces, Atmos. Chem. Phys., 14, 5271-5294, doi:10.5194/acp-14-5271-2014, 2014.

Wang, Y., Liu, X., Hoose, C., and Wang, B.: Different contact angle distributions for heterogeneous ice nucleation in the Community Atmospheric Model version 5, Atmos. Chem. Phys., 14, 1041110430, doi:10.5194/acp-14-10411-2014, 2014.

Whitby, K.: The physical characteristics of sulfur aerosols, Atmos. Environ., 41, 25-49, doi:10.1016/0004-6981(78)90196-8, 2007.

Xie, S., Liu, X., Zhao, C., and Zhang, Y.: Sensitivity of CAM5simulated Arctic clouds and radiation to nucleation parameterization, J. Climate, 26, 5981-5999, doi:10.1175/JCLI-D-1200517.1, 2013. 
Zhang, K., Liu, X., Wang, M., Comstock, J. M., Mitchell, D. L., Mishra, S., and Mace, G. G.: Evaluating and constraining ice cloud parameterizations in CAM5 using aircraft measurements from the SPARTICUS campaign, Atmos. Chem. Phys., 13, 4963-4982, doi:10.5194/acp-13-4963-2013, 2013.
Zuberi, B., Bertram, A., Cassa, C., Molina, L., and Molina, M.: Heterogeneous nucleation of ice in ammonium sulfate-water particles with mineral dust immersions, Geophys. Res. Lett., 29, 142.1-142.4, doi:10.1029/2001GL014289, 2002. 